\title{
Pharmacological Evaluation and Synthesis of New Sulfonamides Derivatives Based on 1,4-Benzodioxane
}

\author{
M. Irshad** ${ }^{1}$, M. A. Abbasi ${ }^{2}$, Aziz-ur-Rehman ${ }^{2}$, M. Akram ${ }^{1}$, Q. Ali ${ }^{1}$, S. Z. \\ Siddiqui $^{2}$, M. Shahid ${ }^{3}$, M. Ashraf ${ }^{4}$, M. A. Lodhi ${ }^{5}$ and S. B. Jamal ${ }^{6}$ \\ ${ }^{1}$ Division of Science and Technology, University of Education, Township Lahore-54770, Pakistan. \\ ${ }^{2}$ Department of Chemistry, Government College University, Lahore-54000, Pakistan. \\ ${ }^{3}$ Department of Chemistry and Biochemistry, University of Agriculture, Faisalabad-38040, Pakistan. \\ ${ }^{4}$ Department of Pharmacy, The Islamia University of Bahawalpur, Bahawalpur-63100, Pakistan. \\ ${ }^{5}$ Department of Biochemistry, Abdul Wali Khan University, Mardan-23200, Pakistan. \\ ${ }^{6}$ Department of Bioinformatics, Islamic International University, Islamabad, Pakistan. \\ *Corresponding Author Email: misbah-irshad@ue.edu.pk \\ Received 18 May 2018, Revised 30 November 2018, Accepted 05 December 2018
}

\begin{abstract}
We report here the synthesis of a series of $N$-aryl-2,3-dihydrobenzo[1,4]dioxine-6-sulfonamide and its $N$-substituted derivatives with benzyl chloride and ethyl iodide. Initially, 2,3dihydrobenzo[1,4]dioxine-6-sulfonyl chloride (1) was subjected to react with various aryl amines (2a-e) to afford parent compounds $N$-aryl-2,3-dihydrobenzo[1,4]dioxine-6-sulfonamide (3a-e). At second step, these parent compounds were reacted with benzyl chloride (4) and ethyl iodide (5) as to synthesize $N$-benzyl- $N$-aryl-2,3-dihydrobenzo[1,4]dioxine-6-sulfonamide (6a-e) and $N$-ethyl- $N$ aryl-2,3-dihydrobenzo[1,4]dioxine-6-sulfonamide (7a-e) in the presence of lithium hydride and $N, N^{\prime}$-dimethylformamide respectively. FT-IR, Nuclear Magnetic Resonance $\left({ }^{1} \mathrm{H}-\mathrm{NMR}\right)$ and Mass Spectrometry (MS) techniques were used to investigate the structures of these synthesized compounds. A fingerprinted study was conducted against some enzymes like butyrylcholinesterase (BChE), acetylcholinesterase ( $\mathrm{AChE}$ ) and lipoxygenase (LOX). This study revealed that most of them demonstrated a moderate activity against butyrylcholinesterase (BChE) and acetylcholinesterase (AChE) however promisingly a good activity against lipoxygenase enzyme was observed. Finally, an antimicrobial and hemolytic activities of these sulfonamides were probed which confirmed that the parent sulfonamides $3 \mathrm{~b}$ have the proficient antimicrobial activities, while the derivatives $6 \mathrm{a}, 7 \mathrm{a}, 7 \mathrm{~b}$ and $7 \mathrm{c}$ explored a good activity against the selected panel of bacterial and fungal species. All the compounds were further computationally docked against (LOX), (BChE) and (AChE) enzymes and these interaction highlighted the importance of sulfonamides in the inhibition of the target enzymes.
\end{abstract}

Keywords: 2,3-dihydrobenzo[1,4]dioxine-6-sulfonyl chloride, Lipoxygenase enzyme, ${ }^{1} \mathrm{H}-\mathrm{NMR}$, EI-MS, Antimicrobial and hemolytic activities, Molecular docking.

\section{Introduction}

As the first effective antibacterial agents sulfonamides were intensively investigated. A broad-spectrum of synthetic bacteriostatic antibiotics is included in this family, which are used against most gram-positive and many gramnegative microorganisms. These compounds are commonly used for therapeutic and prophylactic purposes to fight against common bacterial diseases. Human and veterinary medicine are included in this family [1]. Furthermore, these substances are also used as feed additives in animal husbandry [2]. After tetracyclines sulfonamides are the second most widely used class of veterinary antibiotics in the European countries [3]. 
Sulfonamides inhibit dihydropteroate synthase just like 4-aminobenzoic acid due to structural similarities. After the discovery of penicillin and other antibiotics their utility was reduced, but later they have started to attract attention for their synergic activity, e.g. in the combination with trimethoprim. The combination of sulfamethoxazole (SMX) with trimethoprim exhibit more efficient antibacterial activity due to the sequential inhibition of the bacterial synthesis of tetrahydrofolic acid and thereby disrupting nucleic bases and acids synthesis [4-6]. Because of their ease of administration and non-interaction with defense mechanism of host some derivatives of sulfonamides are extensively used for gastrointestinal and urinary tract infections [7]. In recent times, sulfonamides have been found to be powerful carbonic anhydrase [8], COX-2 $[9,10]$ and caspase inhibitors [11] and have applications in veterinary practices [12].

The 1,4-benzodioxane framework has often been found in biologically active lignans. Silybin [13] and americanin A [14] are use as antihepatotoxic agents; while haedoxan A [15] exhibited insecticidal activity. Silybin, containing large amount of benzodioxane, has been used as a folk medicine in Jammu Kashmir and Europe [16]. This type of natural product, which has shown a variety of bioactivities, is of synthetic interest from many years. Receptor systems are usually composed of multiple subtypes such as $\alpha$ adrenoreceptors. The majority of $\alpha$-adrenoreceptor antagonists displays a competitive mechanism of action and belongs to a variety of different structural classes such as yohimbanes, ergot alkaloids, quinazolines, $N$-arylpiperazines, imidazolines, phenylalkylamines, benzodioxanes, indoles, 1,4-dihydropyridines, hetero-fused 3benzazepines and dibenzoquinolizines [17-19]. Different biological activities like antihepatotoxic [20-22], $\alpha$-adrenergic blocking agent [23], antiinflammatory [24] and $\mathrm{D}_{2}$ antagonist/5-HT1A partial agonist activity are exhibited by compounds containing dioxane ring systems [25].

Additionally, molecular docking approach was used to find out the interaction mode of the synthesized compounds. The purpose of docking methodologies was to forecast the ligand and target complex and to align the molecular database (designed inhibitors) on the basis of binding affinity to that of target. The MOE-Dock was used for docking of all the synthesized inhibitors with the binding site of target enzymes. The eventual objective of molecular docking was to get ligands with better characteristics and have good inhibition potential [26].

This research work is a productive effort to bring in pharmacologically significant compounds. In continuation of our previous work on sulfonamide synthesis [27], the designing of different $N$-substituted sulfonamides derived from 1,4-benzodioxine-6-sulfonyl chloride with an aim to inaugurate new challenges of drug having striking activity for the cure of legionnaires' diseases.

\section{Experimental General}

Griffin and George melting point apparatus was used to record the melting points of the synthesized compounds on an open capillary tube and were not accurate. The progress of reaction and purity was confirmed by TLC; performed on silica gel plates $\left(\mathrm{G}-25-\mathrm{UV}_{254}\right)$. The ethyl acetate and $n$-hexane solvent system in 30: 70 $\%$ was employed as mobile phase. Detection was carried out at $254 \mathrm{~nm}$ and ceric sulphate was used as developing reagent. The FT-IR spectra were conducted on a Jasco-320-A spectrophotometer and results were interpreted in $\mathrm{cm}^{-1}$. On a Bruker spectrometers ${ }^{1} \mathrm{H}-\mathrm{NMR}$ spectra were recorded with deuterated chloroform and methanol; the resolution frequency were 300 and $400 \mathrm{MHz}$. Mass spectra statistic were employed on a JMS-HX-110 spectrometer. 2,3-Dihydrobenzo[1,4]dioxine-6sulfonyl chloride, aryl amines and the other electrophilic reagents were purchased from Merck and Alfa Aesar through local suppliers and were used without further purification. All the employed solvents were of analytical grade.

\section{Synthetic Work \\ General procedure for the synthesis of $\mathrm{N}$-aryl- 2,3-dihydrobenzo[1,4]dioxine-6-sulfonamides in aqueous medium (3a-e)}

$1 \mathrm{mmol}$ of various substituted aryl amines (2a-e) were suspended in $50 \mathrm{~mL}$ water in $250 \mathrm{~mL}$ 
round bottom flask. The $\mathrm{pH}$ was maintained at 9.010.0 by adding basic aqueous solution of $\mathrm{Na}_{2} \mathrm{CO}_{3}$ at $25{ }^{\circ} \mathrm{C}$. Then 2,3-dihydrobenzo[1,4]dioxine-6sulfonyl chloride ( $1 \mathrm{mmol}, 0.234 \mathrm{~g} ; 1)$ was added in the reaction mass slowly over $10-15 \mathrm{~min}$. The reaction was conducted by simple stirring at RT and monitored by thin layer chromatography. Conc. $\mathrm{HCl}$ (about $2 \mathrm{~mL}$ ) was added slowly to adjust the $\mathrm{pH}$ to 2.0. The solid product were precipitate out, collected by filtration and flushed with water to afford the precursors sulfonamides (3a-e) on drying.

\section{$N$-(3,5-Dimethylphenyl)-2,3-dihydrobenzo[1,4] dioxine-6-sulfonamide (3a)}

IR $\quad\left(\mathrm{KBr}, \quad \mathrm{cm}^{-1}\right): \quad v_{\max }: 3421 \quad(\mathrm{~N}-\mathrm{H}$, stretching), 3031 (C-H, stretching of aromatic ring), $2918 \quad\left(-\mathrm{CH}_{2^{-}}, \quad\right.$ stretching $), 1621 \quad(\mathrm{C}=\mathrm{C}$, stretching of aromatic ring), $1321 \quad\left(-\mathrm{SO}_{2^{-}}\right.$, stretching), 1115 (C-O-C, stretching of ether); ${ }^{1} \mathrm{H}-$ NMR: $\delta$ (ppm) $7.30(\mathrm{~d}, J=2.0 \mathrm{~Hz}, 1 \mathrm{H}, \mathrm{H}-5), 7.21$ (dd, $J=8.4,2.4 \mathrm{~Hz}, 1 \mathrm{H}, \mathrm{H}-7), 6.85(\mathrm{~d}, J=8.4 \mathrm{~Hz}$, $1 \mathrm{H}, \mathrm{H}-8), 6.71$ (s, 2H, H-2' and H-6'), $6.66(\mathrm{~s}, 1 \mathrm{H}$, $\left.\mathrm{H}-4^{\prime}\right)$, 4.23-4.25 (m, $4 \mathrm{H}, \mathrm{CH}_{2}-2$ and $\left.\mathrm{CH}_{2}-3\right), 2.21$ (s, $6 \mathrm{H}, \mathrm{CH}_{3}-1$ " and $\mathrm{CH}_{3}-2$ "); EIMS: $\mathrm{m} / 2319[\mathrm{M}]^{+}$, $255\left[\mathrm{M}-\mathrm{SO}_{2}\right]^{+}, 214 \quad\left[\mathrm{C}_{6} \mathrm{H}_{3} \mathrm{C}_{2} \mathrm{H}_{4} \mathrm{O}_{2} \mathrm{SO}_{2} \mathrm{NH}\right]^{+}, 199$ $\left[\mathrm{C}_{6} \mathrm{H}_{3} \mathrm{C}_{2} \mathrm{H}_{4} \mathrm{O}_{2} \mathrm{SO}_{2}\right]^{+}, \quad 135 \quad\left[\mathrm{C}_{6} \mathrm{H}_{3} \mathrm{C}_{2} \mathrm{H}_{4} \mathrm{O}_{2}\right]^{+}, \quad 107$ $\left[\mathrm{C}_{6} \mathrm{H}_{3} \mathrm{O}_{2}\right]^{+}, 105\left[\mathrm{C}_{6} \mathrm{H}_{3}\left(\mathrm{CH}_{3}\right)_{2}\right]^{+}, 90\left[\mathrm{C}_{6} \mathrm{H}_{3} \mathrm{CH}_{3}\right]^{+}, 75$ $\left[\mathrm{C}_{6} \mathrm{H}_{3}\right]^{+}, 65\left[\mathrm{C}_{4} \mathrm{H}_{2} \mathrm{CH}_{3}\right]^{+}$. (Calcd. for $\mathrm{C}_{16} \mathrm{H}_{17} \mathrm{NO}_{4} \mathrm{~S}$; 319.3854)

\section{N-(4-Methylphenyl)-2,3-dihydrobenzo[1,4] dioxine-6-sulfonamide (3b)}

IR $\quad\left(\mathrm{KBr}, \quad \mathrm{cm}^{-1}\right): \quad v_{\max }: 3412 \quad(\mathrm{~N}-\mathrm{H}$, stretching), $3022(\mathrm{C}-\mathrm{H}$, stretching of aromatic ring), $2914 \quad\left(-\mathrm{CH}_{2^{-}}\right.$, stretching $), 1617 \quad(\mathrm{C}=\mathrm{C}$, stretching of aromatic ring), $1326 \quad\left(-\mathrm{SO}_{2^{-}}\right.$, stretching), 1145 (C-O-C, stretching of ether); ${ }^{1} \mathrm{H}$ NMR: $\delta$ (ppm) $7.27(\mathrm{~d}, J=2.0 \mathrm{~Hz}, 1 \mathrm{H}, \mathrm{H}-5), 7.19$ $(\mathrm{dd}, J=8.4,2.0 \mathrm{~Hz}, 1 \mathrm{H}, \mathrm{H}-7), 7.03(\mathrm{~d}, J=8.0 \mathrm{~Hz}$, $1 \mathrm{H}, \mathrm{H}-8), 6.93\left(\mathrm{~d}, J=8.0 \mathrm{~Hz}, 2 \mathrm{H}, \mathrm{H}-2^{\prime}\right.$ and $\left.\mathrm{H}-6^{\prime}\right)$, $6.84\left(\mathrm{~d}, J=8.4 \mathrm{~Hz}, 2 \mathrm{H}, \mathrm{H}-3^{\prime}\right.$ and $\left.\mathrm{H}-5^{\prime}\right), 4.22-4.26$ (m, $4 \mathrm{H}, \mathrm{CH}_{2}-2$ and $\mathrm{CH}_{2}-3$ ), 2.26 (s, 3H, $\left.\mathrm{CH}_{3}-1 "\right)$; EIMS: $m / z \quad 305 \quad[\mathrm{M}]^{+}, \quad 241 \quad\left[\mathrm{M}_{-} \mathrm{SO}_{2}\right]^{+}, \quad 214$ $\left[\mathrm{C}_{6} \mathrm{H}_{3} \mathrm{C}_{2} \mathrm{H}_{4} \mathrm{O}_{2} \mathrm{SO}_{2} \mathrm{NH}\right]^{+}, 199 \quad\left[\mathrm{C}_{6} \mathrm{H}_{3} \mathrm{C}_{2} \mathrm{H}_{4} \mathrm{O}_{2} \mathrm{SO}_{2}\right]^{+}$, $135 \quad\left[\mathrm{C}_{6} \mathrm{H}_{3} \mathrm{C}_{2} \mathrm{H}_{4} \mathrm{O}_{2}\right]^{+}, \quad 107 \quad\left[\mathrm{C}_{6} \mathrm{H}_{3} \mathrm{O}_{2}\right]^{+}, \quad 91$ $\left[\mathrm{C}_{6} \mathrm{H}_{4} \mathrm{CH}_{3}\right]^{+}, 76\left[\mathrm{C}_{6} \mathrm{H}_{4}\right]^{+}, 75\left[\mathrm{C}_{6} \mathrm{H}_{3}\right]^{+}, 50\left[\mathrm{C}_{4} \mathrm{H}_{2}\right]^{+}$. (Calcd. for $\mathrm{C}_{15} \mathrm{H}_{15} \mathrm{NO}_{4} \mathrm{~S} ; 305.3654$ ).

\section{$N$-(3-Hydroxyphenyl)-2,3-dihydrobenzo[1,4]} dioxine-6-sulfonamide (3c)

IR $\left(\mathrm{KBr}, \quad \mathrm{cm}^{-1}\right): \quad v_{\max }: 3455 \quad(\mathrm{~N}-\mathrm{H}$, stretching), 3312 (O-H, stretching), 3018 (C-H, stretching of aromatic ring), $2916 \quad\left(-\mathrm{CH}_{2}-\right.$, stretching $), 1612(\mathrm{C}=\mathrm{C}$, stretching of aromatic ring), 1324 (-SO $2_{2-}$, stretching), 1136 (C-O-C, stretching of ether); ${ }^{1} \mathrm{H}-\mathrm{NMR}: \delta$ (ppm) 8.26 (s, $1 \mathrm{H}, \mathrm{O}-\mathrm{H}), 7.28$ (dd, $J=8.4,2.2 \mathrm{~Hz}, 1 \mathrm{H}, \mathrm{H}-7$ ), $7.16(\mathrm{~d}, J=2.4 \mathrm{~Hz}, 1 \mathrm{H}, \mathrm{H}-5), 7.13(\mathrm{~d}, J=8.0 \mathrm{~Hz}$, 1H, H-8), 6.97 (brt, $J=7.8 \mathrm{~Hz}, 1 \mathrm{H}, \mathrm{H}-5$ '), 6.90 (dd, $\left.J=1.2,1.2 \mathrm{~Hz}, 1 \mathrm{H}, \mathrm{H}-2^{\prime}\right), 6.83$ (dd, $J=8.4$, $1.6 \mathrm{~Hz}, 1 \mathrm{H}, \mathrm{H}-4$ '), 6.63 (dd, $J=8.0,1.4 \mathrm{~Hz}, 1 \mathrm{H}$, H-6'), 4.24-4.32 (m, 4H, $\mathrm{CH}_{2}-2$ and $\left.\mathrm{CH}_{2}-3\right)$; EIMS: $\quad m / z \quad 307 \quad[\mathrm{M}]^{+}, \quad 243 \quad\left[\mathrm{M}_{-} \mathrm{SO}_{2}\right]^{+}, \quad 214$ $\left[\mathrm{C}_{6} \mathrm{H}_{3} \mathrm{C}_{2} \mathrm{H}_{4} \mathrm{O}_{2} \mathrm{SO}_{2} \mathrm{NH}\right]^{+}, 199 \quad\left[\mathrm{C}_{6} \mathrm{H}_{3} \mathrm{C}_{2} \mathrm{H}_{4} \mathrm{O}_{2} \mathrm{SO}_{2}\right]^{+}$, $135 \quad\left[\mathrm{C}_{6} \mathrm{H}_{3} \mathrm{C}_{2} \mathrm{H}_{4} \mathrm{O}_{2}\right]^{+}, \quad 107 \quad\left[\mathrm{C}_{6} \mathrm{H}_{3} \mathrm{O}_{2}\right]^{+}, \quad 93$ $\left[\mathrm{C}_{6} \mathrm{H}_{4} \mathrm{OH}\right]^{+}, 76\left[\mathrm{C}_{6} \mathrm{H}_{4}\right]^{+}, 75\left[\mathrm{C}_{6} \mathrm{H}_{3}\right]^{+}, 50\left[\mathrm{C}_{4} \mathrm{H}_{2}\right]^{+}$. Calcd. for $\mathrm{C}_{14} \mathrm{H}_{13} \mathrm{NO}_{5} \mathrm{~S} ; 307.3442$

\section{N-Benzyl-2,3-dihydrobenzo[1,4]dioxine-6- sulfonamide (3d)}

IR $\left(\mathrm{KBr}, \quad \mathrm{cm}^{-1}\right): \quad v_{\max }: 3455 \quad(\mathrm{~N}-\mathrm{H}$, stretching), 3022 (C-H, stretching of aromatic ring), $2913 \quad\left(-\mathrm{CH}_{2^{-}}\right.$, stretching $), 1609 \quad(\mathrm{C}=\mathrm{C}$, stretching of aromatic ring), $1323 \quad\left(-\mathrm{SO}_{2-}\right.$, stretching), 1127 (C-O, stretching of ether); ${ }^{1} \mathrm{H}-$ NMR: $\delta(\mathrm{ppm}) 7.29$ (dd, $J=2.0,8.4 \mathrm{~Hz}, 1 \mathrm{H}, \mathrm{H}-7)$, $7.25(\mathrm{~d}, J=2.0 \mathrm{~Hz}, 1 \mathrm{H}, \mathrm{H}-5), 7.20-7.24(\mathrm{~m}, 5 \mathrm{H}, \mathrm{H}-$ 2 ' to H-6'), 6.92 (d, $J=8.4 \mathrm{~Hz}, 1 \mathrm{H}, \mathrm{H}-8$ ), $4.29-4.30$ (m, 4H, $\mathrm{CH}_{2}-2$ and $\left.\mathrm{CH}_{2}-3\right), 4.01\left(\mathrm{~s}, 2 \mathrm{H}, \mathrm{CH}_{2}-\mathrm{7}^{\prime}\right)$; EIMS: $m / z \quad 305 \quad[\mathrm{M}]^{+}, \quad 241 \quad\left[\mathrm{M}^{+} \mathrm{SO}_{2}\right]^{+}, \quad 228$ $\left[\mathrm{C}_{6} \mathrm{H}_{3} \mathrm{C}_{2} \mathrm{H}_{4} \mathrm{O}_{2} \mathrm{SO}_{2} \mathrm{NHCH}_{2}\right]^{+}, \quad 200 \quad\left[\mathrm{C}_{6} \mathrm{H}_{3} \mathrm{O}_{2} \mathrm{SO}_{2}\right.$ $\left.\mathrm{NHCH}_{2}\right]^{+}, 199\left[\mathrm{C}_{6} \mathrm{H}_{3} \mathrm{C}_{2} \mathrm{H}_{4} \mathrm{O}_{2} \mathrm{SO}_{2}\right]^{+}, 136\left[\mathrm{C}_{6} \mathrm{H}_{3} \mathrm{O}_{2}\right.$ $\left.\mathrm{NHCH}_{2}\right]^{+}, 135\left[\mathrm{C}_{6} \mathrm{H}_{3} \mathrm{C}_{2} \mathrm{H}_{4} \mathrm{O}_{2}\right]^{+}, 107\left[\mathrm{C}_{6} \mathrm{H}_{3} \mathrm{O}_{2}\right]^{+}, 106$ $\left[\begin{array}{lllll}\left.\mathrm{C}_{6} \mathrm{H}_{5} \mathrm{CH}_{2} \mathrm{NH}\right]^{+}, & 77 & {\left[\mathrm{C}_{6} \mathrm{H}_{5}\right.}\end{array}\right]^{+}, \quad 75 \quad\left[\mathrm{C}_{6} \mathrm{H}_{3}\right]^{+}, \quad 51$ $\left[\mathrm{C}_{4} \mathrm{H}_{3}\right]^{+}$. (Calcd. for $\mathrm{C}_{15} \mathrm{H}_{15} \mathrm{NO}_{4} \mathrm{~S} ; 305.3254$ )

\section{$N$-(2-Phenylethyl)-2,3-dihydrobenzo[1,4]dioxine- 6-sulfonamide (3e)}

IR $\left(\mathrm{KBr}, \quad \mathrm{cm}^{-1}\right): \quad v_{\max }: 3398 \quad(\mathrm{~N}-\mathrm{H}$, stretching), $3010(\mathrm{C}-\mathrm{H}$, stretching of aromatic ring $), 2910 \quad\left(-\mathrm{CH}_{2^{-}}\right.$, stretching $), 1610 \quad(\mathrm{C}=\mathrm{C}$, stretching of aromatic ring), $1321 \quad\left(-\mathrm{SO}_{2}\right.$, stretching), 1134 (C-O-C, stretching of ether); ${ }^{1} \mathrm{H}-$ NMR: $\delta(\mathrm{ppm}) 7.31(\mathrm{~d}, J=2.0 \mathrm{~Hz}, 1 \mathrm{H}, \mathrm{H}-5), 7.28$ (dd, $J=8.4,2.0 \mathrm{~Hz}, 1 \mathrm{H}, \mathrm{H}-7), 7.21(\mathrm{~d}, J=8.4 \mathrm{~Hz}$, 
$1 \mathrm{H}, \mathrm{H}-8), 7.06-7.13$ ( $\mathrm{m}, 5 \mathrm{H}, \mathrm{H}-2$ ' to $\left.\mathrm{H}-6^{\prime}\right)$, 4.27$4.28\left(\mathrm{~m}, 4 \mathrm{H}, \mathrm{CH}_{2}-2\right.$ and $\left.\mathrm{CH}_{2}-3\right), 3.21$ (t, $J=6.8$ $\left.\mathrm{Hz}, 2 \mathrm{H}, \mathrm{CH}_{2}-8^{\prime}\right), 2.77$ (t, $\left.J=6.8 \mathrm{~Hz}, 2 \mathrm{H}, \mathrm{CH}_{2}-7^{\prime}\right)$;

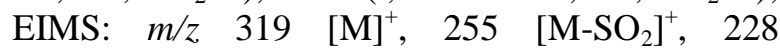
$\left[\mathrm{C}_{6} \mathrm{H}_{3} \mathrm{C}_{2} \mathrm{H}_{4} \mathrm{O}_{2} \mathrm{SO}_{2} \mathrm{NHCH}_{2}\right]^{+}, \quad 200 \quad\left[\mathrm{C}_{6} \mathrm{H}_{3} \mathrm{O}_{2} \mathrm{SO}_{2}\right.$ $\left.\mathrm{NHCH}_{2}\right]^{+}, 199\left[\mathrm{C}_{6} \mathrm{H}_{3} \mathrm{C}_{2} \mathrm{H}_{4} \mathrm{O}_{2} \mathrm{SO}_{2}\right]^{+}, 136\left[\mathrm{C}_{6} \mathrm{H}_{3} \mathrm{O}_{2}\right.$ $\left.\mathrm{NHCH}_{2}\right]^{+}, 135\left[\mathrm{C}_{6} \mathrm{H}_{3} \mathrm{C}_{2} \mathrm{H}_{4} \mathrm{O}_{2}\right]^{+}, 120\left[\mathrm{C}_{6} \mathrm{H}_{5}\left(\mathrm{CH}_{2}\right)_{2}\right.$ $\mathrm{NH}]^{+}, 107\left[\mathrm{C}_{6} \mathrm{H}_{3} \mathrm{O}_{2}\right]^{+}, 91\left[\mathrm{C}_{7} \mathrm{H}_{7}\right]^{+}, 75\left[\mathrm{C}_{6} \mathrm{H}_{3}\right]^{+}, 65$ $\left[\mathrm{C}_{5} \mathrm{H}_{5}\right]^{+}$. (Calcd. for $\mathrm{C}_{16} \mathrm{H}_{17} \mathrm{NO}_{4} \mathrm{~S} ; 319.3854$ )

General procedure for the synthesis of compounds 6a-e and 7a-e:

Lithium hydride $(0.01 \mathrm{~g}, 0.40 \mathrm{mmol})$ was added to a solution of compound $(0.1 \mathrm{~g}, 3 \mathrm{a}-\mathrm{e})$ in $N, N^{N}$-dimethylformamide (DMF, $5 \mathrm{~mL}$ ) at $25{ }^{0} \mathrm{C}$. After that the reaction mixture was stirred for 30 min. The benzyl chloride (4) and ethyl iodide (5) were poured slowly and stirring continued for 1-2 hr. The complete conversion of reactants into derivatives was elucidated from TLC, the subsequent addition of cold distilled water yielded precipitates. The obtained solid was filtered, washed with distilled water and dried to yield the corresponding $\mathrm{N}$-benzyl/ethyl derivatives of $\mathrm{N}$ aryl-2,3-dihydrobenzo[1,4]dioxine-6-sulfonamide (6a-e and 7a-e). In some cases, compound was taken out through solvent extraction method by chloroform.

\section{$N$-Benzyl-N-(3,5-dimethylphenyl)-2,3- dihydrobenzo[1,4]dioxisne-6-sulfonamide (6a)}

IR $\quad\left(\mathrm{KBr}, \quad \mathrm{cm}^{-1}\right): \quad v_{\max }: 3419 \quad(\mathrm{~N}-\mathrm{H}$, stretching), 3031 (C-H, stretching of aromatic ring), $2927 \quad\left(-\mathrm{CH}_{2^{-}}\right.$, stretching $), 1613(\mathrm{C}=\mathrm{C}$, stretching of aromatic ring), $1324 \quad\left(-\mathrm{SO}_{2^{-}}\right.$, stretching), 1122 (C-O-C, stretching of ether); ${ }^{1} \mathrm{H}-$ NMR : $\delta$ (ppm) 7.19-7.24 (m, 5H, H-2" to H-6"), 7.17 (d, $J=2.4 \mathrm{~Hz}, 1 \mathrm{H}, \mathrm{H}-5), 7.11$ (dd, $J=8.0,2.4$ $\mathrm{Hz}, 1 \mathrm{H}, \mathrm{H}-7), 7.08$ (d, $J=8.0 \mathrm{~Hz}, 1 \mathrm{H}, \mathrm{H}-8), 6.98$ (s, 2H, H-2' and H-6'), 6.95 (s, 1H, H-4'), 4.68 (s, $2 \mathrm{H}, \mathrm{CH}_{2}-7$ "), 4.27-4.33 (m, 4H, $\mathrm{CH}_{2}-2$ and $\mathrm{CH}_{2}-3$ ), 2.14 (s, 6H, $\mathrm{CH}_{3}-1$ "' and $\left.\mathrm{CH}_{3}-2 " '\right)$; EIMS: $\mathrm{m} / \mathrm{z} 409$ $[\mathrm{M}]^{+}, 345\left[\mathrm{M}-\mathrm{SO}_{2}\right]^{+}, 304\left[\mathrm{C}_{6} \mathrm{H}_{3} \mathrm{C}_{2} \mathrm{H}_{4} \mathrm{O}_{2} \mathrm{SO}_{2} \mathrm{NCH}_{2}\right.$ $\left.\mathrm{C}_{6} \mathrm{H}_{5}\right]^{+}, 199\left[\mathrm{C}_{6} \mathrm{H}_{3} \mathrm{C}_{2} \mathrm{H}_{4} \mathrm{O}_{2} \mathrm{SO}_{2}\right]^{+}, 135\left[\mathrm{C}_{6} \mathrm{H}_{3} \mathrm{C}_{2} \mathrm{H}_{4}\right.$ $\left.\mathrm{O}_{2}\right]^{+}, \quad 107 \quad\left[\mathrm{C}_{6} \mathrm{H}_{3} \mathrm{O}_{2}\right]^{+}, \quad 105 \quad\left[\mathrm{C}_{6} \mathrm{H}_{3}\left(\mathrm{CH}_{3}\right)_{2}\right]^{+}, \quad 91$ $\left[\mathrm{C}_{7} \mathrm{H}_{7}\right]^{+}, 90\left[\mathrm{C}_{6} \mathrm{H}_{3} \mathrm{CH}_{3}\right]^{+}, 75\left[\mathrm{C}_{6} \mathrm{H}_{3}\right]^{+}, 65\left[\mathrm{C}_{5} \mathrm{H}_{5}\right]^{+}$. (Calcd. for $\mathrm{C}_{23} \mathrm{H}_{23} \mathrm{NO}_{4} \mathrm{~S} ; 409.5187$ )

\section{N-Benzyl-N-(4-methylphenyl)-2,3- dihydrobenzo[1,4]dioxine-6-sulfonamide $(6 \mathrm{~b})$}

IR $\left(\mathrm{KBr}, \quad \mathrm{cm}^{-1}\right): \quad v_{\max }: 3412 \quad(\mathrm{~N}-\mathrm{H}$, stretching), 3065 (C-H, stretching of aromatic ring), $2927 \quad\left(-\mathrm{CH}_{2}-\right.$, stretching $), 1618 \quad(\mathrm{C}=\mathrm{C}$, stretching of aromatic ring), $1327 \quad\left(-\mathrm{SO}_{2}\right.$, stretching),1132 (C-O-C, stretching of ether); ${ }^{1} \mathrm{H}$ NMR: $\delta(\mathrm{ppm}) 7.19(\mathrm{~d}, J=2.4 \mathrm{~Hz}, 1 \mathrm{H}, \mathrm{H}-5), 7.10$ (dd, $J=8.4,2.4 \mathrm{~Hz}, 1 \mathrm{H}, \mathrm{H}-7), 6.98(\mathrm{~d}, J=8.0 \mathrm{~Hz}$, $1 \mathrm{H}, \mathrm{H}-8), 6.86-6.89$ (m, 5H, H-2" to H-6"), 6.84 (d, $J=8.0 \mathrm{~Hz}, 2 \mathrm{H}, \mathrm{H}-2^{\prime}$ and $\left.\mathrm{H}-6^{\prime}\right), 6.81(\mathrm{~d}, J=8.4 \mathrm{~Hz}$, $2 \mathrm{H}, \mathrm{H}-3^{\prime}$ and $\mathrm{H}^{-5}{ }^{\prime}$ ), 4.66 (s, $\left.2 \mathrm{H}, \mathrm{CH}_{2}-7^{\prime \prime}\right), 4.28-4.30$ (m, $4 \mathrm{H}, \mathrm{CH}_{2}-2$ and $\left.\mathrm{CH}_{2}-3\right), 2.23$ (s, 3H, $\left.\mathrm{CH}_{3}-1{ }^{\prime \prime}\right)$;

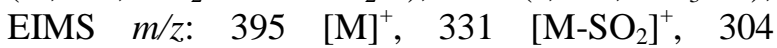
$\left[\mathrm{C}_{6} \mathrm{H}_{3} \mathrm{C}_{2} \mathrm{H}_{4} \mathrm{O}_{2} \mathrm{SO}_{2} \mathrm{NCH}_{2} \mathrm{C}_{6} \mathrm{H}_{5}\right]^{+}, \quad 199\left[\mathrm{C}_{6} \mathrm{H}_{3} \mathrm{C}_{2} \mathrm{H}_{4} \mathrm{O}_{2}\right.$ $\left.\mathrm{SO}_{2}\right]^{+}, 135\left[\mathrm{C}_{6} \mathrm{H}_{3} \mathrm{C}_{2} \mathrm{H}_{4} \mathrm{O}_{2}\right]^{+}, 107 \quad\left[\mathrm{C}_{6} \mathrm{H}_{3} \mathrm{O}_{2}\right]^{+}, 91$ $\left[\mathrm{C}_{7} \mathrm{H}_{7}\right]^{+}, 76\left[\mathrm{C}_{6} \mathrm{H}_{4}\right]^{+}, 75\left[\mathrm{C}_{6} \mathrm{H}_{3}\right]^{+}, 65\left[\mathrm{C}_{5} \mathrm{H}_{5}\right]^{+}, 50$ $\left[\mathrm{C}_{4} \mathrm{H}_{2}\right]^{+}$. (Calcd. for $\mathrm{C}_{22} \mathrm{H}_{21} \mathrm{NO}_{4} \mathrm{~S} ; 395.4925$ )

\section{$N$-Benzyl-N-(3-hydroxyphenyl)-2,3- dihydrobenzo[1,4]dioxine-6-sulfonamide (6c)}

IR $\left(\mathrm{KBr}, \quad \mathrm{cm}^{-1}\right): \quad v_{\max }: 3413 \quad(\mathrm{~N}-\mathrm{H}$, stretching), $3316(\mathrm{O}-\mathrm{H}$, stretching), 3067 (C-H, stretching of aromatic ring), $2931 \quad\left(-\mathrm{CH}_{2}\right.$, stretching $), 1643(\mathrm{C}=\mathrm{C}$, stretching of aromatic ring), 1329 (- $\mathrm{SO}_{2^{-}}$, stretching), 1127 (C-O-C, stretching of ether); ${ }^{1} \mathrm{H}-\mathrm{NMR}$ : $\delta$ (ppm) $8.25(\mathrm{~s}, 1 \mathrm{H}$, $\mathrm{OH}), 7.34(\mathrm{dd}, J=8.4,2.0 \mathrm{~Hz}, 1 \mathrm{H}, \mathrm{H}-7), 7.22(\mathrm{~d}, J$ $=2.4 \mathrm{~Hz}, 1 \mathrm{H}, \mathrm{H}-5), 7.12(\mathrm{~d}, J=8.0 \mathrm{~Hz}, 1 \mathrm{H}, \mathrm{H}-8)$, 7.02 (brt, $J=7.2 \mathrm{~Hz}, 1 \mathrm{H}, \mathrm{H}-5$ '), $6.92-7.01(\mathrm{~m}, 5 \mathrm{H}$, H-2" to H-6"), 6.84 (dd, $J=1.2,1.2 \mathrm{~Hz}, 1 \mathrm{H}, \mathrm{H}-2$ '), $6.68\left(\mathrm{dd}, J=8.0,1.2 \mathrm{~Hz}, 1 \mathrm{H}, \mathrm{H}-4^{\prime}\right), 6.42(\mathrm{dd}, J=$ 8.0, $\left.1.2 \mathrm{~Hz}, 1 \mathrm{H}, \mathrm{H}-6^{\prime}\right), 4.62$ (s, $\left.2 \mathrm{H}, \mathrm{CH}_{2}-7^{\prime \prime}\right), 4.25-$ $4.33\left(\mathrm{~m}, 4 \mathrm{H}, \mathrm{CH}_{2}-2\right.$ and $\mathrm{CH}_{2}-3$ ); EIMS: $m / z 397$ $[\mathrm{M}]^{+}, 333\left[\mathrm{M}-\mathrm{SO}_{2}\right]^{+}, 304\left[\mathrm{C}_{6} \mathrm{H}_{3} \mathrm{C}_{2} \mathrm{H}_{4} \mathrm{O}_{2} \mathrm{SO}_{2} \mathrm{NCH}_{2}\right.$ $\left.\mathrm{C}_{6} \mathrm{H}_{5}\right]^{+}, 199\left[\mathrm{C}_{6} \mathrm{H}_{3} \mathrm{C}_{2} \mathrm{H}_{4} \mathrm{O}_{2} \mathrm{SO}_{2}\right]^{+}, 135\left[\mathrm{C}_{6} \mathrm{H}_{3} \mathrm{C}_{2} \mathrm{H}_{4}\right.$ $\left.\mathrm{O}_{2}\right]^{+}, 107\left[\mathrm{C}_{6} \mathrm{H}_{3} \mathrm{O}_{2}\right]^{+}, 93\left[\mathrm{C}_{6} \mathrm{H}_{4} \mathrm{OH}\right]^{+}, 91\left[\mathrm{C}_{7} \mathrm{H}_{7}\right]^{+}$, $76\left[\mathrm{C}_{6} \mathrm{H}_{4}\right]^{+}, 75\left[\mathrm{C}_{6} \mathrm{H}_{3}\right]^{+}, 65\left[\mathrm{C}_{5} \mathrm{H}_{5}\right]^{+}, 50\left[\mathrm{C}_{4} \mathrm{H}_{2}\right]^{+}$. (Calcd. for $\mathrm{C}_{21} \mathrm{H}_{19} \mathrm{NO}_{5} \mathrm{~S} ; 395.4623$ )

\section{N,N-Dibenzyl-2,3-dihydrobenzo[1,4]dioxine-6- sulfonamide (6d)}

IR $\left(\mathrm{KBr}, \mathrm{cm}^{-1}\right): v_{\max }: 3412(\mathrm{~N}-\mathrm{H}$, stretching), 3034 (C-H, stretching of aromatic ring), 2945 ($\mathrm{CH}_{2^{-}}$, stretching $), 1613 \quad(\mathrm{C}=\mathrm{C}$, stretching of aromatic ring), 1327 (-SO $\mathrm{SO}_{2-,}$ stretching), 1135 (C$\mathrm{O}$, stretching of ether); ${ }^{1} \mathrm{H}-\mathrm{NMR}: \delta(\mathrm{ppm}) 7.33$ (dd, $J=2.0,8.0 \mathrm{~Hz}, 1 \mathrm{H}, \mathrm{H}-7), 7.28(\mathrm{~d}, J=2.4 \mathrm{~Hz}, 1 \mathrm{H}$, 
H-5), 7.04-7.18 (m, 10H, H-2' to H-6' and H-2" to H-6"), 6.98 (d, J=8.4 Hz, 1H, H-8), 4.29-4.32 (m, $4 \mathrm{H}, \mathrm{CH}_{2}-2$ and $\left.\mathrm{CH}_{2}-3\right), 4.28\left(\mathrm{~s}, 4 \mathrm{H}, \mathrm{CH}_{2}-7^{\prime}\right.$ and

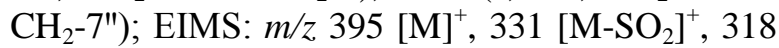
$\left[\mathrm{C}_{6} \mathrm{H}_{3} \mathrm{C}_{2} \mathrm{H}_{4} \mathrm{O}_{2} \mathrm{SO}_{2} \mathrm{NC}_{6} \mathrm{H}_{5}\left(\mathrm{CH}_{2}\right)_{2}\right]^{+}, 290\left[\mathrm{C}_{6} \mathrm{H}_{3} \mathrm{O}_{2} \mathrm{SO}_{2}\right.$ $\left.\mathrm{NC}_{6} \mathrm{H}_{5}\left(\mathrm{CH}_{2}\right)_{2}\right]^{+}, \quad 240 \quad\left[\mathrm{C}_{6} \mathrm{H}_{3} \mathrm{C}_{2} \mathrm{H}_{4} \mathrm{O}_{2} \mathrm{NCH}_{2} \mathrm{C}_{6} \mathrm{H}_{5}\right]^{+}$, $212\left[\mathrm{C}_{6} \mathrm{H}_{3} \mathrm{O}_{2} \mathrm{NCH}_{2} \mathrm{C}_{6} \mathrm{H}_{5}\right]^{+}, 199\left[\mathrm{C}_{6} \mathrm{H}_{3} \mathrm{C}_{2} \mathrm{H}_{4} \mathrm{O}_{2} \mathrm{SO}_{2}\right]^{+}$, $135\left[\mathrm{C}_{6} \mathrm{H}_{3} \mathrm{C}_{2} \mathrm{H}_{4} \mathrm{O}_{2}\right]^{+}, 107\left[\mathrm{C}_{6} \mathrm{H}_{3} \mathrm{O}_{2}\right]^{+}, 91\left[\mathrm{C}_{7} \mathrm{H}_{7}\right]^{+}, 77$

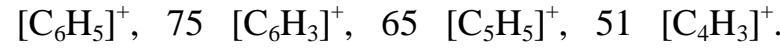
(Calcd. for $\mathrm{C}_{22} \mathrm{H}_{21} \mathrm{NO}_{4} \mathrm{~S} ; 395.4821$ )

\section{N-Benzyl-N-(2-phenylethyl)-2,3-dihydrobenzo [1,4]dioxine-6-sulfonamide (6e)}

IR $\left(\mathrm{KBr}, \mathrm{cm}^{-1}\right): \quad v_{\max }: 3423 \quad(\mathrm{~N}-\mathrm{H}$, stretching), 3043 (C-H, stretching of aromatic ring), $2921\left(-\mathrm{CH}_{2^{-}}, \quad\right.$ stretching $), 1618 \quad(\mathrm{C}=\mathrm{C}$, stretching of aromatic ring), $1328 \quad\left(-\mathrm{SO}_{2}\right.$, stretching), 1142 (C-O-C, stretching of ether); ${ }^{1} \mathrm{H}$ NMR: $\delta$ (ppm) 7.32 (dd, $J=8.4,2.0 \mathrm{~Hz}, 1 \mathrm{H}, \mathrm{H}-7)$, $7.26(\mathrm{~d}, J=2.4 \mathrm{~Hz}, 1 \mathrm{H}, \mathrm{H}-5), 7.17$ (d, $J=8.0 \mathrm{~Hz}$, $1 \mathrm{H}, \mathrm{H}-8), 6.91-7.15\left(\mathrm{~m}, 10 \mathrm{H}, \mathrm{H}-2^{\prime}\right.$ to $\mathrm{H}-6{ }^{\prime}$ and $\mathrm{H}-$ 2" to H-6"), 4.31 (s, $4 \mathrm{H}, \mathrm{CH}_{2}-2$ and $\left.\mathrm{CH}_{2}-3\right), 4.20$ (s, 2H, $\left.\mathrm{CH}_{2}-7^{\prime \prime}\right), 2.72\left(\mathrm{t}, J=7.6 \mathrm{~Hz}, 2 \mathrm{H}, \mathrm{CH}_{2}-8^{\prime}\right)$, $2.58\left(\mathrm{t}, J=7.6 \mathrm{~Hz}, 2 \mathrm{H}, \mathrm{CH}_{2}-7^{\prime}\right)$; EIMS: $m / z 409$ $[\mathrm{M}]^{+}, \quad 345 \quad\left[\mathrm{M}-\mathrm{SO}_{2}\right]^{+}, \quad 318 \quad\left[\mathrm{C}_{6} \mathrm{H}_{3} \mathrm{C}_{2} \mathrm{H}_{4} \mathrm{O}_{2} \mathrm{SO}_{2} \mathrm{~N}\right.$ $\left.\mathrm{C}_{6} \mathrm{H}_{5}\left(\mathrm{CH}_{2}\right)_{2}\right]^{+}, \quad 290 \quad\left[\mathrm{C}_{6} \mathrm{H}_{3} \mathrm{O}_{2} \mathrm{SO}_{2} \mathrm{NC}_{6} \mathrm{H}_{5}\left(\mathrm{CH}_{2}\right)_{2}\right]^{+}$, $254 \quad\left[\mathrm{C}_{6} \mathrm{H}_{3} \mathrm{C}_{2} \mathrm{H}_{4} \mathrm{O}_{2} \mathrm{NC}_{6} \mathrm{H}_{5}\left(\mathrm{CH}_{2}\right)_{2}\right]^{+}, \quad 226 \quad\left[\mathrm{C}_{6} \mathrm{H}_{3} \mathrm{O}_{2}\right.$ $\left.\mathrm{NC}_{6} \mathrm{H}_{5}\left(\mathrm{CH}_{2}\right)_{2}\right]^{+}, \quad 199 \quad\left[\mathrm{C}_{6} \mathrm{H}_{3} \mathrm{C}_{2} \mathrm{H}_{4} \mathrm{O}_{2} \mathrm{SO}_{2}\right]^{+}, \quad 135$ $\left[\mathrm{C}_{6} \mathrm{H}_{3} \mathrm{C}_{2} \mathrm{H}_{4} \mathrm{O}_{2}\right]^{+}, 107 \quad\left[\mathrm{C}_{6} \mathrm{H}_{3} \mathrm{O}_{2}\right]^{+}, 91 \quad\left[\mathrm{C}_{7} \mathrm{H}_{7}\right]^{+}, 77$ $\left[\mathrm{C}_{6} \mathrm{H}_{5}\right]^{+}, 75\left[\mathrm{C}_{6} \mathrm{H}_{3}\right]^{+}, 65 \quad\left[\mathrm{C}_{5} \mathrm{H}_{5}\right]^{+}, \quad 51 \quad\left[\mathrm{C}_{4} \mathrm{H}_{3}\right]^{+}$. (Calcd. for $\mathrm{C}_{23} \mathrm{H}_{23} \mathrm{NO}_{4} \mathrm{~S} ; 409.5187$ ).

\section{N-(3,5-Dimethylphenyl)-N-ethyl-2,3-} dihydrobenzo[1,4]dioxine-6-sulfonamide (7a)

IR $\quad\left(\mathrm{KBr}, \mathrm{cm}^{-1}\right): \quad v_{\max }: 3428 \quad(\mathrm{~N}-\mathrm{H}$, stretching), 3021 (C-H, stretching of aromatic ring), $2927 \quad\left(-\mathrm{CH}_{2^{-}}, \quad\right.$ stretching), $1623 \quad(\mathrm{C}=\mathrm{C}$, stretching of aromatic ring), $1328 \quad\left(-\mathrm{SO}_{2}-\right.$, stretching), 1127 (C-O-C, stretching of ether); ${ }^{1} \mathrm{H}-$ NMR: $\delta$ (ppm) 7.06 (dd, $J=8.4,2.4 \mathrm{~Hz}, 1 \mathrm{H}, \mathrm{H}-7)$, $7.01(\mathrm{~d}, J=2.4 \mathrm{~Hz}, 1 \mathrm{H}, \mathrm{H}-5), 6.95(\mathrm{~d}, J=8.4 \mathrm{~Hz}$, $1 \mathrm{H}, \mathrm{H}-8), 6.62$ (s, 2H, H-2' and H-6'), 6.59 (s, 1H, H-4'), 4.27-4.33 (m, 4H, $\mathrm{CH}_{2}-2$ and $\left.\mathrm{CH}_{2}-3\right), 3.54$ (q, $\left.J=7.2 \mathrm{~Hz}, 2 \mathrm{H}, \mathrm{CH}_{2}-1^{\prime \prime}\right), 2.23\left(\mathrm{~s}, 6 \mathrm{H}, \mathrm{CH}_{3}-1^{\prime \prime \prime}\right.$ and $\left.\mathrm{CH}_{3}-2^{\prime \prime \prime}\right), 1.01\left(\mathrm{t}, J=7.2 \mathrm{~Hz}, 3 \mathrm{H}, \mathrm{CH}_{3}-2^{\prime \prime}\right)$; $\begin{array}{llllll}\text { EIMS: } m / z & 347 & {[\mathrm{M}]^{+},} & 283 & {\left[\mathrm{M}_{-} \mathrm{SO}_{2}\right]^{+},} & 268\end{array}$ $\left[\mathrm{C}_{6} \mathrm{H}_{3} \mathrm{C}_{2} \mathrm{H}_{4} \mathrm{O}_{2} \mathrm{NCH}_{2} \mathrm{C}_{6} \mathrm{H}_{3}\left(\mathrm{CH}_{3}\right)_{2}\right]^{+}, 242 \quad\left[\mathrm{C}_{6} \mathrm{H}_{3} \mathrm{C}_{2} \mathrm{H}_{4}\right.$ $\left.\mathrm{O}_{2} \mathrm{SO}_{2} \mathrm{NC}_{2} \mathrm{H}_{5}\right]^{+}, 240\left[\mathrm{C}_{6} \mathrm{H}_{3} \mathrm{O}_{2} \mathrm{NCH}_{2} \mathrm{C}_{6} \mathrm{H}_{3}\left(\mathrm{CH}_{3}\right)_{2}\right]^{+}$,
$227 \quad\left[\mathrm{C}_{6} \mathrm{H}_{3} \mathrm{C}_{2} \mathrm{H}_{4} \mathrm{O}_{2} \mathrm{SO}_{2} \mathrm{NCH}_{2}\right]^{+}, \quad 199 \quad\left[\mathrm{C}_{6} \mathrm{H}_{3} \mathrm{C}_{2} \mathrm{H}_{4}\right.$ $\left.\mathrm{O}_{2} \mathrm{SO}_{2}\right]^{+}, 135\left[\mathrm{C}_{6} \mathrm{H}_{3} \mathrm{C}_{2} \mathrm{H}_{4} \mathrm{O}_{2}\right]^{+}, 107\left[\mathrm{C}_{6} \mathrm{H}_{3} \mathrm{O}_{2}\right]^{+}, 105$ $\left[\mathrm{C}_{6} \mathrm{H}_{3}\left(\mathrm{CH}_{3}\right)_{2}\right]^{+}, 90\left[\mathrm{C}_{6} \mathrm{H}_{3} \mathrm{CH}_{3}\right]^{+}, 65\left[\mathrm{C}_{4} \mathrm{H}_{2} \mathrm{CH}_{3}\right]^{+}, 75$ $\left[\mathrm{C}_{6} \mathrm{H}_{3}\right]^{+}$. (Calcd. for $\mathrm{C}_{18} \mathrm{H}_{21} \mathrm{NO}_{4} \mathrm{~S} ; 347.4587$ ).

\section{N-Ethyl-N-(4-methylphenyl)-2,3-dihydrobenzo [1,4]dioxine-6-sulfonamide (7b)}

IR $\left(\mathrm{KBr}, \quad \mathrm{cm}^{-1}\right): \quad v_{\max }: 3443 \quad(\mathrm{~N}-\mathrm{H}$, stretching), 3028 (C-H, stretching of aromatic ring), $2929\left(-\mathrm{CH}_{2^{-}}\right.$, stretching), $1636 \quad(\mathrm{C}=\mathrm{C}$, stretching of aromatic ring), $1324 \quad\left(-\mathrm{SO}_{2-}\right.$, stretching), 1145 (C-O-C, stretching of ether); ${ }^{1} \mathrm{H}-$ NMR : $\delta(\mathrm{ppm}) 7.16(\mathrm{~d}, J=2.0 \mathrm{~Hz}, 1 \mathrm{H}, \mathrm{H}-5), 7.06$ (dd, $J=8.4,2.0 \mathrm{~Hz}, 1 \mathrm{H}, \mathrm{H}-7), 6.99$ (d, $J=8.0 \mathrm{~Hz}$, $1 \mathrm{H}, \mathrm{H}-8), 6.92\left(\mathrm{~d}, J=8.0 \mathrm{~Hz}, 2 \mathrm{H}, \mathrm{H}-2^{\prime}\right.$ and H-6'), $6.86\left(\mathrm{~d}, J=8.8 \mathrm{~Hz}, 2 \mathrm{H}, \mathrm{H}-3^{\prime}\right.$ and H-5'), 4.25-4.28 (m, 4H, $\mathrm{CH}_{2}-2$ and $\left.\mathrm{CH}_{2}-3\right), 3.56(\mathrm{q}, J=7.2 \mathrm{~Hz}$, $\left.2 \mathrm{H}, \mathrm{CH}_{2}-1^{\prime \prime}\right), 2.31$ (s, 3H, $\left.\mathrm{CH}_{3}-1^{\prime \prime \prime}\right), 1.03$ (t, $J=7.2$ $\left.\mathrm{Hz}, 3 \mathrm{H}, \mathrm{CH}_{3}-2^{\prime \prime}\right)$; EIMS: m/z $333\left[\mathrm{M}^{+}, 269\right.$ [M$\left.\mathrm{SO}_{2}\right]^{+}, \quad 254 \quad\left[\mathrm{C}_{6} \mathrm{H}_{3} \mathrm{C}_{2} \mathrm{H}_{4} \mathrm{O}_{2} \mathrm{NCH}_{2} \mathrm{C}_{6} \mathrm{H}_{4} \mathrm{CH}_{3}\right]^{+}, \quad 242$ $\left[\mathrm{C}_{6} \mathrm{H}_{3} \mathrm{C}_{2} \mathrm{H}_{4} \mathrm{O}_{2} \mathrm{NSO}_{2} \mathrm{C}_{2} \mathrm{H}_{5}\right]^{+}, 227 \quad\left[\mathrm{C}_{6} \mathrm{H}_{3} \mathrm{C}_{2} \mathrm{H}_{4} \mathrm{O}_{2} \mathrm{SO}_{2}\right.$ $\left.\mathrm{NCH}_{2}\right]^{+}, \quad 226 \quad\left[\mathrm{C}_{6} \mathrm{H}_{3} \mathrm{O}_{2} \mathrm{NCH}_{2} \mathrm{C}_{6} \mathrm{H}_{4} \mathrm{CH}_{3}\right]^{+}, \quad 199$ $\left[\mathrm{C}_{6} \mathrm{H}_{3} \mathrm{C}_{2} \mathrm{H}_{4} \mathrm{O}_{2} \mathrm{SO}_{2}\right]^{+}, \quad 135 \quad\left[\mathrm{C}_{6} \mathrm{H}_{3} \mathrm{C}_{2} \mathrm{H}_{4} \mathrm{O}_{2}\right]^{+}, 107$ $\left[\mathrm{C}_{6} \mathrm{H}_{3} \mathrm{O}_{2}\right]^{+}, 91\left[\mathrm{C}_{6} \mathrm{H}_{4} \mathrm{CH}_{3}\right]^{+}, 76\left[\mathrm{C}_{6} \mathrm{H}_{4}\right]^{+}, 75\left[\mathrm{C}_{6} \mathrm{H}_{3}\right]^{+}$, $50\left[\mathrm{C}_{4} \mathrm{H}_{2}\right]^{+}$. (Calcd. for $\mathrm{C}_{17} \mathrm{H}_{19} \mathrm{NO}_{4} \mathrm{~S} ; 333.4542$ ).

\section{N-Ethyl-N-(3-hydroxyphenyl)-2,3-dihydrobenzo [1,4]dioxine-6-sulfonamide (7c)}

IR $\left(\mathrm{KBr}, \quad \mathrm{cm}^{-1}\right): \quad v_{\max }: 3454 \quad(\mathrm{~N}-\mathrm{H}$, stretching), 3067 (C-H, stretching of aromatic ring), $3312(\mathrm{O}-\mathrm{H}, \quad$ stretching $), 2912 \quad\left(-\mathrm{CH}_{2^{-}}\right.$, stretching), $1645(\mathrm{C}=\mathrm{C}$, stretching of aromatic ring), 1327 (-SO $2^{-}$, stretching), 1156 (C-O-C, stretching of ether); ${ }^{1} \mathrm{H}-\mathrm{NMR}: \delta$ (ppm) 8.20 (s, 1H, O-H), 7.30 (dd, $J=8.4,1.6 \mathrm{~Hz}, 1 \mathrm{H}, \mathrm{H}-7), 7.25$ (d, $J$ $=2.4 \mathrm{~Hz}, 1 \mathrm{H}, \mathrm{H}-5), 7.19(\mathrm{~d}, J=8.0 \mathrm{~Hz}, 1 \mathrm{H}, \mathrm{H}-8)$, 7.00 (brt, $\left.J=7.6 \mathrm{~Hz}, 1 \mathrm{H}, \mathrm{H}-5^{\prime}\right), 6.87$ (dd, $J=1.2$, $2.0 \mathrm{~Hz}, 1 \mathrm{H}, \mathrm{H}-2 '), 6.64$ (dd, $J=1.2,8.0 \mathrm{~Hz}, 1 \mathrm{H}, \mathrm{H}-$ 4'), 6.45 (dd, $J=8.0,1.2 \mathrm{~Hz}, 1 \mathrm{H}, \mathrm{H}-6 '), 4.28-4.31$ (m, 4H, $\mathrm{CH}_{2}-2$ and $\left.\mathrm{CH}_{2}-3\right), 3.51$ (q, $J=7.0 \mathrm{~Hz}$, $\left.2 \mathrm{H}, \mathrm{CH}_{2}-1 "\right), 0.95$ (t, $J=7.2 \mathrm{~Hz}, 3 \mathrm{H}, \mathrm{CH}_{3}-2^{\prime \prime}$ ); EIMS: $m / z \quad 335\left[\mathrm{M}^{+}, \quad 271 \quad\left[{\mathrm{M}-\mathrm{SO}_{2}}^{+}, \quad 256\right.\right.$ $\left[\mathrm{C}_{6} \mathrm{H}_{3} \mathrm{C}_{2} \mathrm{H}_{4} \mathrm{O}_{2} \mathrm{NCH}_{2} \mathrm{C}_{6} \mathrm{H}_{4} \mathrm{OH}\right]^{+}, 242 \quad\left[\mathrm{C}_{6} \mathrm{H}_{3} \mathrm{C}_{2} \mathrm{H}_{4} \mathrm{O}_{2}\right.$ $\left.\mathrm{NSO}_{2} \mathrm{C}_{2} \mathrm{H}_{5}\right]^{+}, 228 \quad\left[\mathrm{C}_{6} \mathrm{H}_{3} \mathrm{O}_{2} \mathrm{NCH}_{2} \mathrm{C}_{6} \mathrm{H}_{4} \mathrm{OH}\right]^{+}, 227$ $\left[\mathrm{C}_{6} \mathrm{H}_{3} \mathrm{C}_{2} \mathrm{H}_{4} \mathrm{O}_{2} \mathrm{SO}_{2} \mathrm{NCH}_{2}\right]^{+}, 199\left[\mathrm{C}_{6} \mathrm{H}_{3} \mathrm{C}_{2} \mathrm{H}_{4} \mathrm{O}_{2} \mathrm{SO}_{2}\right]^{+}$, $135 \quad\left[\mathrm{C}_{6} \mathrm{H}_{3} \mathrm{C}_{2} \mathrm{H}_{4} \mathrm{O}_{2}\right]^{+}, \quad 107 \quad\left[\mathrm{C}_{6} \mathrm{H}_{3} \mathrm{O}_{2}\right]^{+}, \quad 93$ $\left[\mathrm{C}_{6} \mathrm{H}_{4} \mathrm{OH}\right]^{+}, 76\left[\mathrm{C}_{6} \mathrm{H}_{4}\right]^{+}, 75\left[\mathrm{C}_{6} \mathrm{H}_{3}\right]^{+}, 50\left[\mathrm{C}_{4} \mathrm{H}_{2}\right]^{+}$. (Calcd. for $\mathrm{C}_{16} \mathrm{H}_{17} \mathrm{NO}_{5} \mathrm{~S} ; 335.3931$ ). 
N-Benzyl-N-ethyl-2,3-dihydrobenzo[1,4]dioxine6-sulfonamide (7d)

IR $\quad\left(\mathrm{KBr}, \quad \mathrm{cm}^{-1}\right): \quad v_{\max }: 3417 \quad(\mathrm{~N}-\mathrm{H}$, stretching), 3034 (C-H, stretching of aromatic ring), $2924 \quad\left(-\mathrm{CH}_{2}-\right.$, stretching $), 1615 \quad(\mathrm{C}=\mathrm{C}$, stretching of aromatic ring), $1326 \quad\left(-\mathrm{SO}_{2}\right.$, stretching), 1128 (C-O, stretching of ether); ${ }^{1} \mathrm{H}-$ NMR: $\delta$ (ppm) 7.42 (dd, $J=2.1,8.4 \mathrm{~Hz}, 1 \mathrm{H}, \mathrm{H}-7$ ), 7.34 (d, $J=2.4 \mathrm{~Hz}, 1 \mathrm{H}, \mathrm{H}-5), 7.28-7.32$ (m, 5H, H$2^{\prime}$ to $\left.\mathrm{H}-6^{\prime}\right), 7.01$ (d, $\left.J=8.4 \mathrm{~Hz}, 1 \mathrm{H}, \mathrm{H}-8\right), 4.23-4.30$ (m, $4 \mathrm{H}, \mathrm{CH}_{2}-2$ and $\left.\mathrm{CH}_{2}-3\right), 4.19$ (s, $\left.2 \mathrm{H}, \mathrm{CH}_{2}-7^{\prime}\right)$, 3.15 (q, $\left.J=7.2 \mathrm{~Hz}, 2 \mathrm{H}, \mathrm{CH}_{2}-1 "\right), 0.88(\mathrm{t}, J=7.2$ $\mathrm{Hz}, 3 \mathrm{H}, \mathrm{CH}_{3}-2$ "); EIMS: $\mathrm{m} / z 333[\mathrm{M}]^{+}, 269$ [M$\left.\mathrm{SO}_{2}\right]^{+}, \quad 256 \quad\left[\mathrm{C}_{6} \mathrm{H}_{3} \mathrm{C}_{2} \mathrm{H}_{4} \mathrm{O}_{2} \mathrm{SO}_{2} \mathrm{NCH}_{2} \mathrm{C}_{2} \mathrm{H}_{5}\right]^{+}, \quad 241$ $\left[\mathrm{C}_{6} \mathrm{H}_{3} \mathrm{C}_{2} \mathrm{H}_{4} \mathrm{O}_{2} \mathrm{SO}_{2} \mathrm{~N}\left(\mathrm{CH}_{2}\right)_{2}\right]^{+}, \quad 199 \quad\left[\mathrm{C}_{6} \mathrm{H}_{3} \mathrm{C}_{2} \mathrm{H}_{4} \mathrm{O}_{2}\right.$ $\left.\mathrm{SO}_{2}\right]^{+}, 135 \quad\left[\mathrm{C}_{6} \mathrm{H}_{3} \mathrm{C}_{2} \mathrm{H}_{4} \mathrm{O}_{2}\right]^{+}, 107\left[\mathrm{C}_{6} \mathrm{H}_{3} \mathrm{O}_{2}\right]^{+}, 77$ $\left[\mathrm{C}_{6} \mathrm{H}_{5}\right]^{+}, \quad 75 \quad\left[\mathrm{C}_{6} \mathrm{H}_{3}\right]^{+}, \quad 51 \quad\left[\mathrm{C}_{4} \mathrm{H}_{3}\right]^{+}$. (Calcd. for $\mathrm{C}_{17} \mathrm{H}_{19} \mathrm{NO}_{4} \mathrm{~S} ; 333.4234$ )

\section{$\mathrm{N}$-Ethyl-N-(2-phenylethyl)-2,3-dihydrobenzo [1,4]dioxine-6-sulfonamide (7e)}

IR $\left(\mathrm{KBr}, \mathrm{cm}^{-1}\right): v_{\max }: 3429(\mathrm{~N}-\mathrm{H}$, stretching), 3027 (C-H, stretching of aromatic ring), 2921 ($\mathrm{CH}_{2^{-}}$, stretching $), 1619 \quad(\mathrm{C}=\mathrm{C}$, stretching of aromatic ring), 1328 (- $\mathrm{SO}_{2^{-}}$,stretching), 1145 (C-OC,stretching of ether); ${ }^{1} \mathrm{H}-\mathrm{NMR}: \delta$ (ppm) 7.27 (dd, $J=8.2,2.4 \mathrm{~Hz}, 1 \mathrm{H}, \mathrm{H}-7), 7.19(\mathrm{~d}, J=2.4 \mathrm{~Hz}, 1 \mathrm{H}$, H-5), 6.99-7.25 (m, 5H, H-2' to H-6'), 6.97 (d, $J=$ $8.0 \mathrm{~Hz}, 1 \mathrm{H}, \mathrm{H}-8), 4.27-4.30\left(\mathrm{~m}, 4 \mathrm{H}, \mathrm{CH}_{2}-2\right.$ and $\left.\mathrm{CH}_{2}-3\right), 3.30$ (t, $\left.J=7.2 \mathrm{~Hz}, 2 \mathrm{H}, \mathrm{CH}_{2}-8^{\prime}\right), 3.20$ (q, $\left.J=7.2 \mathrm{~Hz}, 2 \mathrm{H}, \mathrm{CH}_{2}-1 "\right), 2.81(\mathrm{t}, J=7.2 \mathrm{~Hz}, 2 \mathrm{H}$, $\left.\mathrm{CH}_{2}-7^{\prime}\right), 1.07$ (t, $\left.J=7.2 \mathrm{~Hz}, 3 \mathrm{H}, \mathrm{CH}_{3}-2^{\prime \prime}\right)$; EIMS: $\mathrm{m} / \mathrm{z} 347[\mathrm{M}]^{+}, 283\left[\mathrm{M}-\mathrm{SO}_{2}\right]^{+}, 256\left[\mathrm{C}_{6} \mathrm{H}_{3} \mathrm{C}_{2} \mathrm{H}_{4} \mathrm{O}_{2}\right.$ $\left.\mathrm{SO}_{2} \mathrm{NCH}_{2} \mathrm{C}_{2} \mathrm{H}_{5}\right]^{+}, \quad 255 \quad\left[\mathrm{C}_{6} \mathrm{H}_{3} \mathrm{O}_{2} \mathrm{~N}\left(\mathrm{CH}_{2}\right)_{2} \mathrm{C}_{2} \mathrm{H}_{5} \mathrm{C}_{6}\right.$ $\left.\mathrm{H}_{5}\right]^{+}, \quad 241 \quad\left[\mathrm{C}_{6} \mathrm{H}_{3} \mathrm{C}_{2} \mathrm{H}_{4} \mathrm{O}_{2} \mathrm{SO}_{2} \quad \mathrm{~N}\left(\mathrm{CH}_{2}\right)_{2}\right]^{+}, \quad 199$ $\left[\mathrm{C}_{6} \mathrm{H}_{3} \mathrm{C}_{2} \mathrm{H}_{4} \mathrm{O}_{2} \mathrm{SO}_{2}\right]^{+}, \quad 135 \quad\left[\mathrm{C}_{6} \mathrm{H}_{3} \mathrm{C}_{2} \mathrm{H}_{4} \mathrm{O}_{2}\right]^{+}, \quad 107$ $\left[\mathrm{C}_{6} \mathrm{H}_{3} \mathrm{O}_{2}\right]^{+}, 91\left[\mathrm{C}_{7} \mathrm{H}_{7}\right]^{+}, 75\left[\mathrm{C}_{6} \mathrm{H}_{3}\right]^{+}, 65\left[\mathrm{C}_{5} \mathrm{H}_{5}\right]^{+}$. (Calcd. for $\mathrm{C}_{18} \mathrm{H}_{21} \mathrm{NO}_{4} \mathrm{~S} ; 347.4587$ ).

\section{Enzyme inhibition studies}

Butyrylcholinesterase and Acetylcholinesterase assay

The BChE and AChE inhibition activity were carried out by taking $100 \mu \mathrm{L}$ of the reaction mixture containing $60 \mu \mathrm{L}$ of $50 \mathrm{mM} \mathrm{Na} \mathrm{NPO}_{4}$ buffer bearing $\mathrm{pH} 7.7,10 \mu \mathrm{L}$ of both the test compound and $\mathrm{AChE} / \mathrm{BChE}$ having strength of 0.5
$\mathrm{mM}$ were added in each cell. After mixing the contents were pre-read at $405 \mathrm{~nm}$ and incubated at $37^{\circ} \mathrm{C}$ for few mins. After incubation the $10 \mu \mathrm{L}$ of substrate was planted; butyrylthiocholine chloride for $\mathrm{BChE}$ and acetylthiocholine iodide for $\mathrm{AChE}$ along with $10 \mu \mathrm{L}$ DTNB $\left(0.5 \mathrm{mM}\right.$ well $\left.{ }^{-1}\right)$. After 15 min of incubation at $37{ }^{\circ} \mathrm{C}$. Using Eserine as control the absorbance was computed at $405 \mathrm{~nm}$ [28]. The \% inhibition was found by

$$
\text { Inhibition }(\%)=\frac{\text { Control }- \text { Test }}{\text { Control }} \times 100
$$

Where Control $=$ Total enzyme activity without inhibitor

Test = Activity in the presence of test compound

\section{Lipoxygenase assay}

Lipoxygenase (LOX) activity was assayed according to the method [29-31] with small modifications. Baicalein $\left(0.5 \mathrm{mM}^{\text {well }}{ }^{-1}\right)$ was used as a positive control. $\mathrm{IC}_{50}$ values were calculated using the same procedure as mentioned for butyrylcholinesterase and acetylcholinesterase enzyme.

\section{Statistical analysis}

All the measurements were completed in triplicate and statistical analysis was performed by Microsoft Excel 2010. Results are offered as mean \pm sem.

\section{Antimicrobial activity \\ Microbial strains}

All the synthesized samples were individually tested against a set of microorganisms, including two gram-positive bacteria: Staphylococcus aureus (S. aureus), and Bacillus subtilis (B. subtilis); two gram-negative bacteria: Escherichia coli (E. coli) and Pasteurella multocida (P. multocida) (local isolate) and four pathogenic fungi, Candida albicans (C. albican), Microsporumcanis (M. canis), Aspergillus flavus (A. flavus) and Fusarium solani (F.solani). The pure bacterial and fungal strains were obtained from Department of Clinical Medicine and 
Surgery, University of Agriculture, Faisalabad, Pakistan. Purity and identity were verified by the Department of Microbiology, University of Agriculture, Faisalabad, Pakistan. In agar nutrient the bacterial and fungal strains were cultured at $37^{\circ} \mathrm{C}$ and $28^{\circ} \mathrm{C}$, respectively. The incubation lasts for a day [32].

\section{Disc diffusion method}

The antimicrobial activity of the synthesized compounds was determined by disc diffusion method [32]. Amoxycillin $(30 \mu \mathrm{g} / \mathrm{dish})$ (Oxoid, UK) and Flumequine (30 $\mu \mathrm{g} /$ disk) (Oxoid, UK) were used as positive reference for bacteria and fungi, respectively to compare sensitivity of strain/isolate in analyzed microbial species. Plates, after $2 \mathrm{hr}$ at $4{ }^{\circ} \mathrm{C}$, were incubated at $37^{\circ} \mathrm{C}$ for $18 \mathrm{hr}$ for bacteria and at $28{ }^{\circ} \mathrm{C}$ for $24 \mathrm{hr}$ for fungal strains. Antimicrobial activity was evaluated by measuring the diameter of the growth inhibition zones (zone reader) in millimeters for the organisms and comparing to the controls.

\section{Hemolytic activity}

Hemolytic activity of the compound was studied by taking $3 \mathrm{~mL}$ of freshly obtained heparinized human blood was collected from volunteers after consent, counseling and bovine from the Department of Clinical Medicine and Surgery, University of Agriculture, Faisalabad, Pakistan. Blood was centrifuged for $5 \mathrm{~min}$ and cells were washed three times with $5 \mathrm{~mL}$ of chilled $\left(\begin{array}{ll}4 & { }^{\circ} \mathrm{C}\end{array}\right)$ sterile isotonic phosphate-buffered saline (PBS) with $\mathrm{pH}$ 7.4. Erythrocytes were maintained $10^{8}$ cells per mL for each assay. $100 \mu \mathrm{L}$ of each compound was mixed with human $\left(10^{8}\right.$ cells $/ \mathrm{mL}$ ) separately. Samples were incubated for $35 \mathrm{~min}$ at $37{ }^{\circ} \mathrm{C}$ and agitated after $10 \mathrm{~min}$. Immediately after incubation the samples were placed on ice for $5 \mathrm{~min}$ then centrifuged for $5 \mathrm{~min}$. Supernatant $100 \mu \mathrm{L}$ were taken from each tube and diluted 10 times with chilled $\left(4{ }^{\circ} \mathrm{C}\right)$ PBS. Triton X$100(0.1 \% \mathrm{v} / \mathrm{v})$ was taken as positive control and PBS was taken as negative control and pass through the same process. The absorbance was noted at $576 \mathrm{~nm}$ using $\mu$ Quant (Bioteck, USA). The \% RBCs lysis for each sample was calculated [33].

\section{Molecular docking}

The structures of all the synthesized inhibitors were constructed using MOE-Builder tool. The default parameters of MOE-Dock program were used for the molecular docking of the ligands. Ligands were allowed to be flexible in order to find the accurate conformations of the ligands and to obtain minimum energy structures. At the end of docking, the best conformations of the ligands were analyzed for their binding interactions.

\section{Results and Discussion Chemistry}

In the undertaken research, a series of heterocyclic compounds containing benzodioxane nucleus were synthesized as scheme 1 . The parent compounds $N$-aryl-2,3-dihydrobenzo [1,4]dioxine6 -sulfonamide (3a-e), were prepared by a process similar to the known literature procedure [34] using 1,4-benzodioxane-6-sulfonyl chloride (1) and aryl amines (2a-e). Reactions of 3a-e with different electrophiles yielded a series of $\mathrm{N}$ benzyl/ethyl- $N$-aryl-2,3-dihydrobenzo[1,4]dioxine6-sulfonamide (6a-e and 7a-e) as represented in Scheme 1. Synthesis of all derivatives 6a-e and 7ae was performed in DMF ( $N, N^{\prime}$-dimethylformamide) using lithium hydride ( $\mathrm{LiH})$ as the base. Complete conversion was achieved within 30 to 70 min by stirring. The products were isolated by adding cold distilled water in the reaction mixture and filtering off the precipitated solid. In some cases, compound was taken out through solvent extraction method by chloroform. Parent compound 3a was synthesized as light grey powder with yield of $92 \%$ and melting point of $152-154{ }^{\circ} \mathrm{C}$. HR-MS showing molecular ion peak at $\mathrm{m} / \mathrm{z} \quad 319.3772$ confirming the formula $\mathrm{C}_{16} \mathrm{H}_{17} \mathrm{NO}_{4} \mathrm{~S}$ of a compound and total proton count was corroborated from ${ }^{1} \mathrm{H}-\mathrm{NMR}$ spectrum. The FT-IR spectrum showed stretching frequencies at $3421,3031,1621,1321$ and $1115 \mathrm{~cm}^{-1}$ provided the clues for the presence of $\mathrm{N}-\mathrm{H}$ of sulfonamide, $\mathrm{C}-\mathrm{H}$ and $\mathrm{C}=\mathrm{C}$ of aromatic ring, $-\mathrm{SO}_{2}$ of sulfonyl group and $\mathrm{C}-\mathrm{O}-\mathrm{C}$ of ether functionalities respectively. The EI-MS gave characteristic peaks at $\mathrm{m} / \mathrm{z} 199$ and 90 which were attributed to the formation of $\mathrm{C}_{6} \mathrm{H}_{3} \mathrm{C}_{2} \mathrm{H}_{4} \mathrm{O}_{2} \mathrm{SO}_{2}^{+}$and $\mathrm{C}_{6} \mathrm{H}_{3} \mathrm{CH}_{3}{ }^{+}$ 
cations respectively. In the aromatic region of the ${ }^{1} \mathrm{H}-\mathrm{NMR}$ spectrum signals appeared at $\delta 7.30(\mathrm{~d}, J$ $=2.0 \mathrm{~Hz}, 1 \mathrm{H}, \mathrm{H}-5), 7.21(\mathrm{dd}, J=8.4,2.4 \mathrm{~Hz}, 1 \mathrm{H}$, $\mathrm{H}-7)$ and $6.85(\mathrm{~d}, J=8.4 \mathrm{~Hz}, 1 \mathrm{H}, \mathrm{H}-8)$ were assigned to the phenyl ring attached to sulfonyl group; whereas three aromatic signals at $\delta 6.71$ (s, $2 \mathrm{H}, \mathrm{H}-2^{\prime}$ and $\left.\mathrm{H}-6^{\prime}\right), 6.66$ (s, 1H, H-4') were assigned to the benzene ring of 3,5-dimethylphenyl group. The signals appeared at $4.23-4.25(\mathrm{~m}, 4 \mathrm{H}$, $\mathrm{CH}_{2}-2$ and $\left.\mathrm{CH}_{2}-3\right)$, and $2.21\left(\mathrm{~s}, 6 \mathrm{H}, \mathrm{CH}_{3}-1 "\right.$ and $\mathrm{CH}_{3}-2$ ") indicated the presence of 1,4-dioxane nucleus and two methyl groups attached to third and fifth position of aniline in the molecule contributed to the aliphatic region of the spectrum. On these backgrounds, the structure was assigned to the parent compound $N$-(3,5-Dimethylphenyl)2,3-dihydrobenzo[1,4]dioxine-6-sulfonamide 3a. Similarly, the structure of other compounds was characterized on above said spectral techniques. The physical data is provided in Table 1 . The mass fragmentation pattern of $N$-(2-Phenylethyl)-2,3dihydrobenzo[1,4]dioxine-6-sulfonamide (3e) is given in Fig. 1.

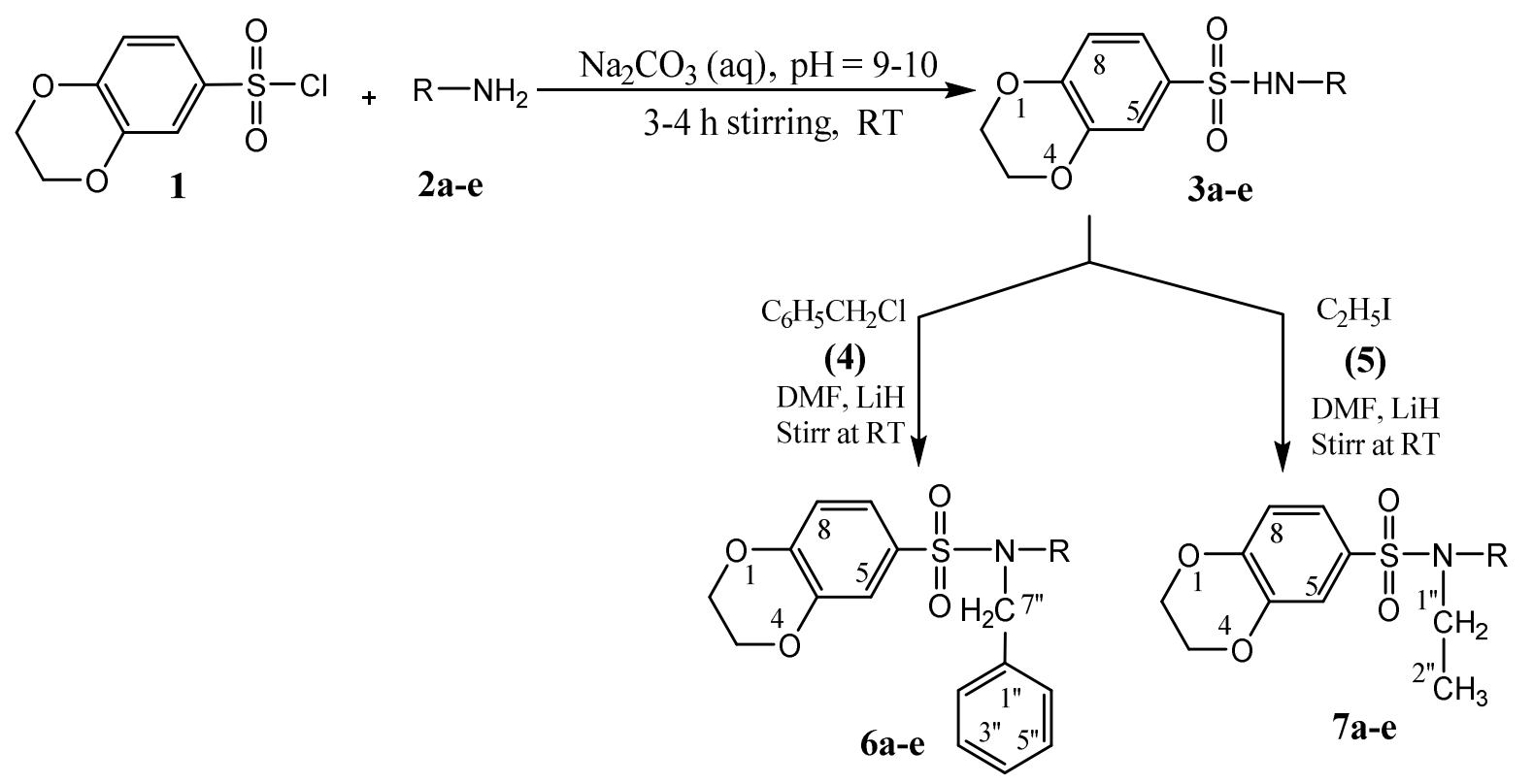

Compound

Scheme 1: Synthetic scheme of various sulfonamides bearing benzodioxane nucleus 
Pak. J. Anal. Environ. Chem. Vol. 19, No. 2 (2018)

Table 1. Physical data of the synthesized compounds.

\begin{tabular}{|c|c|c|c|c|c|c|}
\hline Compound & Physical state & Color & Mol. formula & Mol. Wt. & M.P. ${ }^{\circ} \mathrm{C}$ & $\%$ yield \\
\hline $3 a$ & Solid & Light grey & $\mathrm{C}_{16} \mathrm{H}_{17} \mathrm{NO}_{4} \mathrm{~S}$ & 319 & $152-154$ & 92 \\
\hline $3 b$ & Solid & White & $\mathrm{C}_{15} \mathrm{H}_{15} \mathrm{NO}_{4} \mathrm{~S}$ & 305 & $119-121$ & 87 \\
\hline $3 \mathrm{c}$ & Solid & Light grey & $\mathrm{C}_{14} \mathrm{H}_{13} \mathrm{NO}_{5} \mathrm{~S}$ & 307 & $112-114$ & 75 \\
\hline $3 d$ & Solid & White & $\mathrm{C}_{15} \mathrm{H}_{15} \mathrm{NO}_{4} \mathrm{~S}$ & 305 & $78-80$ & 86 \\
\hline $3 e$ & Solid & White & $\mathrm{C}_{16} \mathrm{H}_{17} \mathrm{NO}_{4} \mathrm{~S}$ & 319 & $91-93$ & 94 \\
\hline $6 a$ & Solid & White & $\mathrm{C}_{23} \mathrm{H}_{23} \mathrm{NO}_{4} \mathrm{~S}$ & 409 & $241-243$ & 89 \\
\hline $6 b$ & Sticky solid & Dark brown & $\mathrm{C}_{22} \mathrm{H}_{21} \mathrm{NO}_{4} \mathrm{~S}$ & 395 & - & 79 \\
\hline $6 c$ & Gummy solid & Yellowish brown & $\mathrm{C}_{21} \mathrm{H}_{19} \mathrm{NO}_{5} \mathrm{~S}$ & 397 & - & 71 \\
\hline $6 \mathrm{~d}$ & Solid & Yellow & $\mathrm{C}_{22} \mathrm{H}_{21} \mathrm{NO}_{4} \mathrm{~S}$ & 395 & - & 70 \\
\hline $6 e$ & Solid & White & $\mathrm{C}_{23} \mathrm{H}_{23} \mathrm{NO}_{4} \mathrm{~S}$ & 409 & $152-154$ & 92 \\
\hline $7 \mathrm{a}$ & Solid & Off white & $\mathrm{C}_{18} \mathrm{H}_{21} \mathrm{NO}_{4} \mathrm{~S}$ & 347 & $260-262$ & 93 \\
\hline $7 b$ & Sticky solid & Brown & $\mathrm{C}_{17} \mathrm{H}_{19} \mathrm{NO}_{4} \mathrm{~S}$ & 333 & - & 74 \\
\hline $7 \mathrm{c}$ & Sticky solid & Dark brown & $\mathrm{C}_{16} \mathrm{H}_{17} \mathrm{NO}_{5} \mathrm{~S}$ & 335 & - & 71 \\
\hline $7 d$ & Sticky solid & Yellowish brown & $\mathrm{C}_{17} \mathrm{H}_{19} \mathrm{NO}_{4} \mathrm{~S}$ & 333 & - & 73 \\
\hline $7 \mathrm{e}$ & Solid & White & $\mathrm{C}_{18} \mathrm{H}_{21} \mathrm{NO}_{4} \mathrm{~S}$ & 347 & $80-82$ & 89 \\
\hline
\end{tabular}

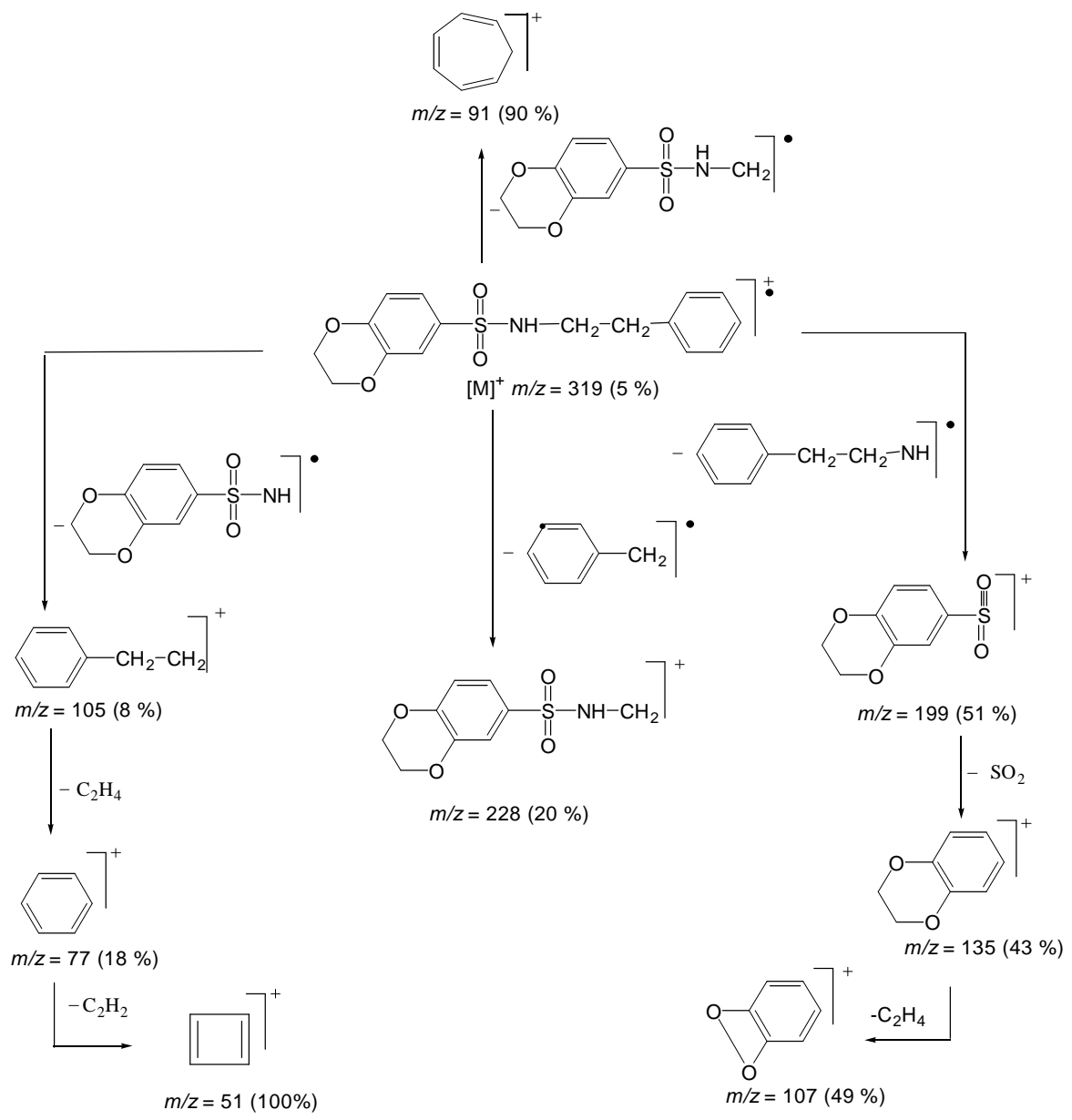

Figure 1. Mass fragmentation pattern of $N$-(2-phenylethyl)-2,3-dihydrobenzo[1,4]dioxine-6-sulfonamide (3e) 


\section{Enzyme inhibition}

The screening of all the synthesized compounds against butyrylcholinesterase enzyme revealed that only three compounds showed good activity, $\mathrm{N}$-benzyl- $\mathrm{N}$-(3-hydroxyphenyl)-2,3dihydrobenzo[1,4]dioxine-6-sulfonamide $(6 \mathrm{c}), \mathrm{N}$ benzyl-2,3-dihydrobenzo[1,4]dioxine-6-sulfonamide (3d), $N$-benzyl- $N$-(3,5-dimethylphenyl)-2,3dihydrobenzo [1,4] dioxine-6-sulfonamide (6a) having $\mathrm{IC}_{50}$ values of $71.27 \pm 0.01,198.21 \pm 0.11$ and $259.61 \pm 0.01 \mu \mathrm{moles} / \mathrm{L}$ respectively, comparative to eserine (Table 2). The activity of the these compound was the most probably due to presence of hydroxyl group at third position of aniline ring in $6 \mathrm{c}$, benzyl group in $3 \mathrm{~d}$ and two alkyl groups at third and fifth position of aniline ring in 6a along with benzyl group attached to nitrogen of sulfonamide. For screening, against acetylcholineesterase enzyme, among all the synthesized compounds only three demonstrated better activity i.e. $\quad N$-benzyl- $N$-(3-hydroxyphenyl)-2,3-dihydrobe nzo[1,4]dioxine-6-sulfonamide (6c), $N$-(3-hydrox yphenyl)-2,3-dihydrobenzo[1, 4]dioxine-6-sulfona mide (3c) and $N$-ethyl- $N$-(3,5-dimethylphenyl)-2,3dihydrobenzo[1,4]dioxine-6-sulfonamide having $\mathrm{IC}_{50}$ values of $99.93 \pm 0.19,174.51 \pm 0.15$, and $189.81 \pm 0.08 \mu \mathrm{moles} / \mathrm{L}$, respectively compare- ative to standard. The proficient activity of first and second compound was the most likely due to occurrence of hydroxyl group at meta position of aniline ring and that of third compound was likely due to the presence of two alkyl groups on aniline ring along with ethyl group attached to nitrogen of sulfonamide. Against lipoxygenase enzyme, all the synthesized compounds showed beneficially good activity but the most active were $N$-(3,5dimethylphenyl)-2,3-dihydrobenzo[1,4] dioxine-6sulfonamide (3a), $N$-(3,5-dimethylphenyl)- $N$-ethyl2,3-dihydrobenzo[1,4]dioxine-6-sulfonamide (7a) and $N, N$-dibenzyl-2,3-dihydrobenzo[1,4]dioxine-6sulfonamide (6d) having $\mathrm{IC}_{50}$ values of $91.25 \pm 0.16,65.25 \pm 0.16$ and $81.91 \pm 0.21, \mu$ moles $/ \mathrm{L}$ respectively, comparative to baicalein. The presented activity of first compound was the most probably due to occurrence of two alkyl groups, at third and fifth positions of aniline ring, that of second and third compounds was credibly due to the presence of two alkyl groups at $3^{\text {rd }} / 5^{\text {th }}$ of position of aniline ring and benzyl group, along with benzyl and ethyl group respectively attached to nitrogen of sulfonamide. All the parent compounds (3a-e) can be further utilized for the synthesis of new derivatives with other different electrophiles to enhance their biological, antimicrobial and other activities.

Table 2. Bioactivity study of synthesized molecules.

\begin{tabular}{|c|c|c|c|c|c|c|c|c|c|}
\hline \multirow[b]{2}{*}{ C. No. } & \multicolumn{3}{|c|}{ BChE } & \multicolumn{3}{|c|}{$\overline{A C h E}$} & \multicolumn{3}{|c|}{ LOX } \\
\hline & $\begin{array}{c}\text { Conc/well } \\
(\mathrm{mM})\end{array}$ & $\begin{array}{c}\text { Inhibition } \\
(\%)\end{array}$ & $\begin{array}{c}\text { IC }_{50} \\
(\text { Hmoles } / L)\end{array}$ & $\begin{array}{l}\text { Conc. } \\
(\mathrm{mM})\end{array}$ & $\begin{array}{c}\text { Inhibition } \\
(\%)\end{array}$ & $\begin{array}{c}I_{50} \\
(\mu \text { moles } / L)\end{array}$ & $\begin{array}{c}\text { Conc./well } \\
(\mathrm{mM})\end{array}$ & $\begin{array}{c}\text { Inhibition } \\
(\%)\end{array}$ & $\begin{array}{c}I_{50} \\
(\mu \mathrm{moles} / \mathrm{L})\end{array}$ \\
\hline $3 \mathbf{a}$ & 0.5 & $5.65 \pm 0.35$ & - & 0.5 & $55.98 \pm 0.15$ & $<400$ & 0.5 & $79.17 \pm 0.63$ & $91.25 \pm 0.16$ \\
\hline $\mathbf{3 b}$ & 0.5 & $56.79 \pm 0.48$ & $<400$ & 0.5 & $18.52 \pm 0.77$ & - & 0.5 & $53.51 \pm 0.11$ & $<400$ \\
\hline $3 c$ & 0.5 & $11.89 \pm 0.14$ & - & 0.5 & $72.31 \pm 0.11$ & $174.51 \pm 0.15$ & 0.5 & $65.53 \pm 0.28$ & $209.81 \pm 0.13$ \\
\hline 3d & 0.5 & $67.58 \pm 0.14$ & $198.21 \pm 0.11$ & 0.5 & $15.33 \pm 0.57$ & Nil & 0.5 & $51.99 \pm 0.51$ & $<400$ \\
\hline $3 e$ & 0.25 & $57.91 \pm 0.87$ & $<400$ & 0.5 & $18.47 \pm 0.87$ & - & 0.5 & $70.29 \pm 0.91$ & $104.11 \pm 0.17$ \\
\hline $6 \mathbf{a}$ & 0.5 & $63.56 \pm 0.36$ & $259.61 \pm 0.01$ & 0.5 & $52.66 \pm 0.69$ & $<400$ & 0.5 & $39.87 \pm 0.16$ & - \\
\hline $6 b$ & 0.5 & $50.24 \pm 0.46$ & $<500$ & 0.5 & $13.33 \pm 0.22$ & $>500$ & 0.5 & $34.64 \pm 0.51$ & - \\
\hline $6 c$ & 0.5 & $79.12 \pm 0.13$ & $71.27 \pm 0.01$ & 0.5 & $87.79 \pm 0.11$ & $99.93 \pm 0.19$ & 0.5 & $12.64 \pm 0.11$ & - \\
\hline 6d & 0.5 & $44.05 \pm 0.11$ & - & 0.5 & $37.93 \pm 0.87$ & - & 0.5 & $85.61 \pm 0.19$ & $81.91 \pm 0.21$ \\
\hline $6 e$ & 0.5 & $30.81 \pm 0.11$ & - & 0.5 & $10.26 \pm 0.92$ & - & 0.5 & $30.39 \pm 0.24$ & - \\
\hline $7 \mathbf{a}$ & 0.5 & $53.72 \pm 0.15$ & $<400$ & 0.5 & $70.14 \pm 0.18$ & $189.81 \pm 0.08$ & 0.5 & $88.64 \pm 0.14$ & $65.25 \pm 0.16$ \\
\hline $7 \mathbf{b}$ & 0.5 & $50.99 \pm 0.63$ & $<500$ & 0.5 & $11.67 \pm 0.87$ & $>500$ & 0.5 & $20.01 \pm 0.17$ & - \\
\hline $7 c$ & 0.5 & $28.28 \pm 0.62$ & - & 0.5 & $16.91 \pm 0.85$ & - & 0.5 & $45.74 \pm 0.61$ & - \\
\hline $7 d$ & 0.5 & $43.29 \pm 0.19$ & - & 0.5 & $36.61 \pm 0.69$ & - & 0.5 & $72.44 \pm 0.18$ & $101.51 \pm 0.31$ \\
\hline $7 e$ & 0.5 & $36.39 \pm 0.13$ & $>500$ & 0.5 & $75.19 \pm 0.18$ & $301.2 \pm 0.05$ & 0.5 & $27.38 \pm 0.34$ & - \\
\hline Control & Eserine & $82.82 \pm 1.09$ & $0.85 \pm 0.0001$ & Eserine & $91.29 \pm 1.17$ & $0.04 \pm 0.0001$ & Baicalein & $93.79 \pm 1.27$ & $22.4 \pm 1.3$ \\
\hline
\end{tabular}

Note: $\mathrm{IC}_{50}$ values (concentration at which there is $50 \%$ enzyme inhibition) of compounds were calculated using EZ-Fit Enzyme kinetics software (Perella Scientific Inc. Amherst, USA).

$\mathrm{LOX}=$ Lipoxygenase. AChE $=$ Acetyl cholinesterase. $\quad$ BChE $=$ Butyryl cholinesterase. 


\section{Antimicrobial activity}

The in vitro antimicrobial properties of the parent compounds and their derivatives were tested (Table 3). Among the parent compounds 3a showed the antimicrobial activity against the selected panel of both bacterial and fungal species. Regarding the derivatives (6a-e) series; 6a showed higher activities in comparison to the rest of the members of its series. $7 \mathrm{a}$ and $7 \mathrm{~b}$ were the members of 7a-e series which were the moderate to good active against both bacterial and fungal strains and $7 \mathrm{c}$ was relatively efficient antifungal candidate against selected strains. The remaining compounds possess very low or no activity against the assessed microorganisms. The highest hemolytic activity was shown by $6 a(92 \%)$ but lower than the positive control (Triton-X-100). The lowest activity was shown by $6 \mathrm{~b}$ and $7 \mathrm{c}(1.2 \%$ and $1.6 \%$ respectively) but higher than the negative controls PBS. These synthesized molecules inhibit the synthesis of cell wall protein of bacteria; interfering their growth and also break down red blood cells of host. Those antibacterial candidates would be selected; that have low hemolytic activity and high antibacterial or antifungal potential. On the basis of the previous results we may assume that the synthesized sulfonamides may be suitable leads for further improvement to address different targets.

Table 3. Antibacterial and antifungal studies on synthesized compounds.

\begin{tabular}{|c|c|c|c|c|c|c|c|c|c|}
\hline \multirow[t]{2}{*}{ Compound } & \multicolumn{4}{|c|}{ Antibacterial activity } & \multicolumn{5}{|c|}{ Antifungal activity } \\
\hline & $\begin{array}{c}\text { Staphylococcs } \\
\text { aureus }\end{array}$ & $\begin{array}{l}\text { Bacillus } \\
\text { subtilis }\end{array}$ & $\begin{array}{l}\text { Pasturella } \\
\text { multocida }\end{array}$ & $\begin{array}{l}\text { Escherichia } \\
\text { coli }\end{array}$ & $\begin{array}{c}\text { Hemolytic activity } \\
\text { (Mean) } \% \pm \text { S.D }\end{array}$ & $\begin{array}{l}\text { Candida } \\
\text { albicans }\end{array}$ & $\begin{array}{l}\text { Microspor } \\
\text { umcanis }\end{array}$ & $\begin{array}{l}\text { Aspergillus } \\
\text { flavus }\end{array}$ & $\begin{array}{c}\text { Fusarium } \\
\text { solani }\end{array}$ \\
\hline \multicolumn{6}{|c|}{$\begin{array}{c}\text { Zone of inhibition } \\
(\mathrm{mm})\end{array}$} & \multicolumn{4}{|c|}{ Zone of inhibition (mm) } \\
\hline $3 \mathrm{a}$ & - & - & - & - & $86.844 \pm 0.417$ & - & - & - & - \\
\hline $3 b$ & 14 & 12 & 14 & 14 & $86.765 \pm 0.212$ & 17 & 12 & 14 & 18 \\
\hline $3 \mathrm{c}$ & - & - & - & - & $90.164 \pm 0.278$ & - & - & - & - \\
\hline $3 \mathrm{~d}$ & - & - & - & - & $74.426 \pm 0.031$ & - & - & - & - \\
\hline $3 \mathrm{e}$ & - & - & - & - & $88.901 \pm 0.025$ & - & - & - & - \\
\hline $6 a$ & 18 & 14 & 16 & 16 & $92.973 \pm 7.063$ & 19 & 14 & 15 & 14 \\
\hline $6 \mathrm{~b}$ & - & - & - & - & $1.202 \pm 0.155$ & - & - & - & - \\
\hline $6 c$ & - & - & - & - & $87.720 \pm 0.284$ & - & - & - & - \\
\hline $6 \mathrm{~d}$ & - & - & - & - & $87.345 \pm 0.246$ & - & - & - & - \\
\hline $6 e$ & - & - & - & - & $91.956 \pm 1.425$ & - & - & - & - \\
\hline $7 \mathrm{a}$ & 16 & 18 & 16 & 16 & $92.723 \pm 8.405$ & 16 & 18 & 16 & 16 \\
\hline $7 \mathrm{~b}$ & 19 & 22 & 20 & 18 & $58.557 \pm 2.983$ & 11 & 13 & 10 & 14 \\
\hline $7 \mathrm{c}$ & - & - & - & - & $1.639 \pm 0.093$ & 12 & 10 & 15 & 12 \\
\hline $7 \mathrm{~d}$ & - & - & - & - & $86.678 \pm 0.250$ & - & - & - & - \\
\hline $7 \mathrm{e}$ & - & - & - & - & $87.565 \pm 1.425$ & - & - & - & - \\
\hline Streptomycin & 30 & 28 & 28 & 30 & Flumequine & 29 & 27 & 26 & 31 \\
\hline PBS & & & & & $0.00 \pm 0.0$ & & & & \\
\hline $\begin{array}{l}\text { Triton } \\
\text { (toxicity) }\end{array}$ & & & & & $100 \pm 0.0$ & & & & \\
\hline
\end{tabular}




\section{Molecular docking}

The results obtained from in silico approach were also favoring the fact that synthesized sulfonamides have shown good interaction with the target site. The interaction analysis shown that in every compound, the sulfonamide group is contributing in the interactions. The interaction of compound $3 \mathrm{~b}$ with the active site of LOX and AChE is shown in Fig. 2 and Fig. 3. As depicted from stature; compound $3 \mathrm{~b}$ showed good interaction with the amino acids residues of binding cavity. Against LOX, the both oxygen of sulfonyl group showed interactions with the Histidine 528 residue; whereas one oxygen of dioxane ring displayed attachment with Histidine 523 of LOX. In an AChE display; one doubly bonded oxygen of sulfonyl group exhibited hydrogen bonding with the serine 122 residue; while second one demonstrated attachment with Tyrosine 121 and phenylene group of benzodi-oxane displayed bonding to phenylalanine 130 amino acid. Thus molecular docking results were well in correlation with the experimentally determined data of enzyme inhibition against AChE and LOX.

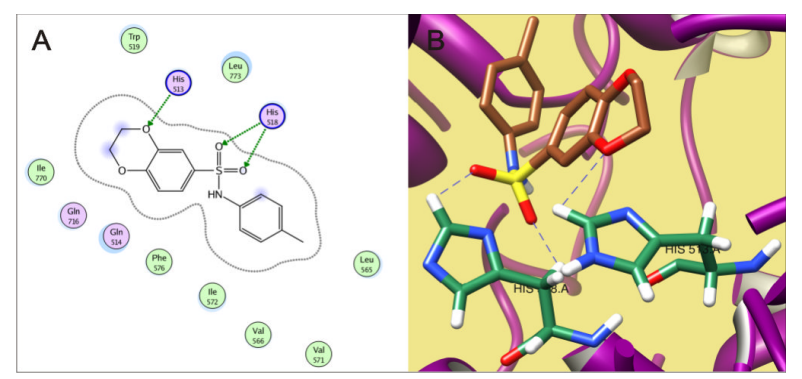

Figure 2. The interaction between compound $3 \mathrm{~b}$ and lipoxygenase. 2D and 3D pose of the complex is shown in figure $A$ and $B$ respectively

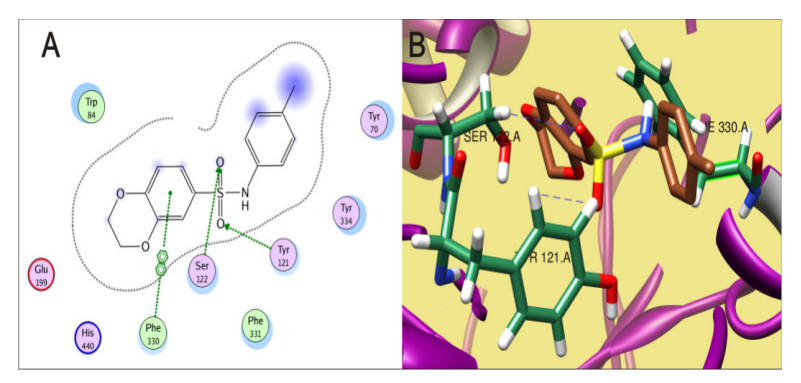

Figure 3. The interaction between compound $3 \mathrm{~b}$ and acetylcholinesterase. 2D and 3D pose of the complex is shown in figure $A$ and $B$ respectively

\section{Conclusion}

The new series of sulfonamide bearing 1,4-benzodioxane ring were reported. The targets were characterized by FT-IR, ${ }^{1} \mathrm{H}-\mathrm{NMR}$ and EIMS. All the compounds were screened for their antibacterial and antifungal activity by disc diffusion method. Compounds $3 \mathrm{a}, 6 \mathrm{a}$ and $7 \mathrm{~b}$ exhibited good antimicrobial activity amongst all in comparison to standard (streptomycin). Compound $6 \mathrm{c}$ was more active against both $\mathrm{BchE}$ and AchE, while 7a exhibited good inhibition potential against LOX.

\section{Acknowledgements}

The Authors extend their appreciation to the Higher Education Commission of Pakistan for financial support.

\section{References}

1. G. L. Mandell and M. A. Sande, Pergamon Press, New York, (1990) 1047. https://books.google.com.pk/books/ISBN=00 80527523

2. S. Wang, H. Y. Zhang, L. Wang, Z. J. Duan and I. Kennedy, Food Addit. Contam., 23 (2006) 362. doi:10.1080/02652030500499359

3. A. K. Sarmah, M. T. Meyer and A. B. A. Boxall, Chemosphere, 65 (2006) 725. doi:http://dx.doi.org/10.1016/j

4. X. L. Wang, K. Wan and C. H. Zhou, Eur. J. Med. Chem., 45 (2010) 4631. doi: 10.1016/j.ejmech.2010.07.031

5. Epstein, M. Amodio-Groton and N. S. Sadick, J. Am. Acad. Dermatol., 37 (1997) 149.

https://www.ncbi.nlm.nih.gov/pubmed/9270 499

6. J. D. Smilack, Mayo Clin. Proc., 74 (1999) 730 https://doi.org/10.4065/74.7.730

7. M. E. Gadad, C. S. Mahajanshetti, S. Nimbalkar and A. Raichurkar, Eur. $J$. Med. Chem., 35 (2000) 853. https://doi.org/10.1016/S02235234(00)00166-5 
8. B. L. Wilkinson, L. F. Bornaghi, T. A. Houston, A. Innocenti, C. Vullo, C. T. Supuran and S. A. Poulsen, J. Med. Chem, 50 (2007) 1651.

doi: $10.1021 / \mathrm{jm} 061320 \mathrm{~h}$

9. C. Almansa, J. Bartroli, J. Belloc, F. L. Cavalcanti, R. Ferrando, L. A. Gomez, I. Ramis, E. Carceller, M. Merlos and J. J. Garcia-Rafanell, Med. Chem., 47 (2004) 5579.

doi: $10.1021 / \mathrm{jm} 040844 \mathrm{j}$

10. D.Vullo, De Luca, V. Scozzafava, A. Carginale, V. Rossi, M. Supuran, C. T. Capasso, Bioorg. Med. Chem., 21 (2013) 4521.

doi: 10.1016/j.bmc.2013.05.042.

11. W. Chu, J. Rothfuss, A. Avignon, C. Zeng, D. Zhou, R. S. Hotchkiss and R.H. Mach, $J$. Med. Chem., 50 (2007) 3751.

doi: 10.1021/jm070506t

12. El-Dien, G.G. Mohamed, E. Khaled and E.Y. Z. Frag, J. Adv. Res., 1 (2010) 215. doi: 10.1016/j.jare.2010.05.005

13. W. Chu, J. Zhang, C. Zeng, J. Rothfuss, Z. Tu, Y. Chu, D. E. Reichert, M. J. Welch and R. H. Mach, J. Med. Chem., 48 (2005) 7637. https://pubs.acs.org/doi/abs/10.1021/jm0506 $\underline{625}$

14. D. J. Abraham, S. Takagi, R. D. Rosenstein, R. Shiono, H. Wagner, L. Horhammer, O. Seligmann and N. R. Farnsworth, Tetrahedron Lett, 31 (1970) 2675. pubs.rsc.org/en/content/articlepdf/2003/ob/b 300099k

15. W. Gu, X. Chen, X. Pan, A. S. C. Chan and Y. Teng-Kuei, Tetrahedron: Asymmetry, 11 (2000) 2801. doi: 10.1021/o1034415b

16. W. Chu, J. Zhang, C. Zeng, J. Rothfuss, Z. Tu, Y. Chu, D. E. Reichert, M. J. Welch and R. H. Mach, J. Med. Chem., 48 (2005) 7637. doi: $10.1021 / \mathrm{jm} 0506625$

17. B. Kenny, S. Ballard, J. Blagg and D. Fox, $J$. Med. Chem., 40 (1997) 1293. doi: $10.1021 / \mathrm{jm} 960697 \mathrm{~s}$.

18. R. R. Ruffolo, W. Bondinell and J. P. Hieble, J. Med. Chem., 38 (1995) 3681. http://hyper.ahajournals.org/content/hyperten sionaha/33/2/708.full.pdf
19. A. Leonardi, R. Testa, P. G. De Benedetti, P. Hieble and D. Giardin, Elsevier, Amsterdam (1996) 135.

20. B. Ahmed, S. A. Khan and T. Alam, Pharmazie, 58 (2003) 173. PMID: 12685811,

https://www.ingentaconnect.com/content/govi/ph armaz/2003/00000058/00000003/art00003

21. H. Khalilullah, S. Khan, M.J. Ahsan and B. Ahmed, Korean Chem. Soc. Bull., 33 (2012) 575. doi: $10.5012 /$ bkcs.2012.33.2.575

22. S. A. Khan, B. Ahmad and T. Alam, Pak. J. Pharm. Sci., 19 (2006) 290. PMID: 17105706

23. K. Nikolic, D. Agbaba, Hem. Ind., 66 (2012) 619. doi: 10.2298/HEMIND120221037N

24. M. T. Vazquez, G. Rosell and M. D. Pujol, Pharmaco, 51 (1996) 215. PMID: 8688144

25. L. I. Pilkington and D. Barker, Nat. Prod. Rep, 32 (2015) 1369. doi: 10.1039/c5np00048c.

26. A. Wadood, M. Riaz, S. B. Jamal, M. Shah and M. A. Lodhi, Bioinformation, 9 (2013) 309. doi: 10.6026/97320630009309

27. M. Irshad, M. A. Abbasi, Aziz-ur-Rehman, S. Z. Siddiqui, M. S. Ali, M. Ashraf, T. Ismail, I. Ahmad, S. Hassan, M. A. Lodhi and S. B. Jamal, Pak. J. Pharm. Sci., 29 (2016) 1913.

http://www.pjps.pk/wpcontent/uploads/pdfs/29/6/Paper-4.pdf

28. G. L. Ellman, K. D. Courtney, V. Andres and R. M. Featherstone, Biochem. Pharmacol, 7 (1961) 88. https://doi.org/10.1016/00062952(61)90145-9

29. A. L. Tappel, Arch. Biochem. Biophys., 54 (1955) 266. https://doi.org/10.1016/00039861(55)90039-4

30. H. C. Clapp, A. Banerjee and S. A. Rotenberg, J. Biochem., 24 (1985) 1826. doi: org/10.1021/bi00329a004.

31. C. Kemal, P. Louis-Flemberg, R. R. Krupinski-Olsen and A. L. Shorter, $J$. Biochem., 26 (1987) 7064. doi.org/10.1021/bi00396a031. 
32. CLSI (The clinical Laboratory Standard Institute) J. Clin. Microbiol, 45 (2007) 2752. doi: 10.1128/JCM.00143-07

33. P. Sharma and J. D. Sharma, J. Ethol, 74 (2001) 239. Pubmed/11274824, https://doi.org/10.1016/S0378$\underline{8741(00) 00370-6}$
34. X. Deng and N. S. Mani, Asian J. Pharm. Hea. Sci., 8 (2006) 835. doi: $10.1039 / \mathrm{b} 606127 \mathrm{c}$. 